This is a self-archived version of an original article. This version may differ from the original in pagination and typographic details.

Author(s): Heikkilä, Jussi; Verba, Michael

Title: The role of utility models in patent filing strategies : evidence from European countries

Year: 2018

Version: Accepted version (Final draft)

Copyright: @ 2018 Akadémiai Kiadó, Budapest, Hungary

Rights: In Copyright

Rights url: http://rightsstatements.org/page/lnC/1.0/?language=en

Please cite the original version:

Heikkilä, J., \& Verba, M. (2018). The role of utility models in patent filing strategies : evidence from European countries. Scientometrics, 116(2), 689-719. https://doi.org/10.1007/s11192-

018-2773-z 


\title{
THE ROLE OF UTILITY MODELS IN PATENT FILING STRATEGIES: EVIDENCE FROM EUROPEAN COUNTRIES
}

\author{
Jussi Heikkilä ${ }^{\&}$ Michael Verba² \\ Accepted for publication in Scientometrics. \\ Please quote the published version available at \\ https://doi.org/10.1007/s11192-018-2773-z
}

\begin{abstract}
We examine the role of utility models (UM) in patent filing strategies. With an extensive patent family data from European countries, we explore the structures and characteristics of patent families, which include UMs. A simple typology of patent families with UM members is introduced. We document that the geographical scope of most patent families with UM members is purely national, which is in line with the conventional view that the UM mechanism covers technologically and economically marginal inventions. However, the image of a UM as a signal of a minor invention is an oversimplification. Applicants exhibit a mixture of uses for the UM and there exists a subset of UM filings linked to inventions the inventive step of which meets or exceeds the threshold required for patent protection. Some UMs are members of international patent families, indicating that applicants may have some strategic motives to use UMs in international filing. The findings highlight that both types of IPR documents (UMs and patents) should be taken into account when working with data on patent families, analysing patent filing strategies, and constructing patent-based indicators such as patenting propensities.
\end{abstract}

Keywords: patent, utility model, patent family, priority filing

JEL codes: O31, O34, O38

\footnotetext{
${ }^{1}$ University of Jyväskylä, Jyväskylä University School of Business and Economics, jussi.heikkila@jyu.fi ORCID: 0000-0002-5122-7956

2 Tilburg University, School of Governance, School of Economics and Management, $\underline{\text { M.A.Verba@uvt.nl }}$
} 


\section{Introduction}

Patent filing strategies of patent applicants affect the structures of patent families and an increasing number of studies have started to analyze the phenomenon as availability of patent family data has improved (Stevnsborg and van Pottelsberghe 2007; Martínez 2011; Dechezleprêtre et al. 2017; Cao 2015; Cao et al. 2016). Yet, very little is known about the role of utility models (UM) in patent families. UM systems are not harmonized internationally (Janis 1999) and there is a need to better understand their functioning and impact on competition and innovation activity. This paper is among the first to systematically explore the role of UMs in patent filing strategies in the European context (cf Radauer et al., 2015).

When filing a patent application, the applicant must make a number of important and strategic choices regarding the geographical scope of protection and application process (Guellec and van Pottelsberghe 2002; Frietsch et al. 2013). First, she must choose, at which patent office to file the first patent application (the so-called "priority filing" or "priority" for short; see World Intellectual Property Organization (WIPO) 2008, pp. 243245; de Rassenfosse et al. 2013; Frietsch et al. 2013). ${ }^{3}$ Second, after filing the priority, the applicant must choose within twelve months, at which other patent offices she files subsequent patent applications (hereafter "subsequent filings") for the same technical invention. The priorities and subsequent filing(s) can be linked in many possible ways; directly or indirectly. Each priority and the sequence of subsequent filings representing the same technical invention constitute a patent family (Martínez 2011; Dechezleprêtre et al. 2017). ${ }^{4}$

Filing strategies are options selected by applicants during the patenting process from the choice set made available by the patent system. Among the dimensions of a filing strategy are alternative filing routes, drafting style, and request for expedited processing (van Zeebroeck and van Pottelsberghe 2011; Stevnsborg and van Pottelsberghe de la Potterie 2007). In this study, we consider applicant choice steps regarding the jurisdiction of application, the type of intellectual property protection, and the sequence of applications that determine the patent family structure of the invention. The novelty of the present study is the focus on the role of utility model (UM) members in patent families in European context. Some countries have two-tiered patent protection systems and when a priority or subsequent filing is made in such a system, the patent family can also contain utility models or other types of second tier patent protection. Compared to patents, UMs differ in various essential dimensions: 1) the requirements for acquiring UMs are generally less stringent - that is, the inventive step requirement is usually lower ${ }^{5}$ 2) UMs are characterized by a shorter term of protection, and 3) UMs have a simpler and faster application procedure (see WIPO, 2008, p. 40). In addition, UMs often have lower

\footnotetext{
${ }^{3}$ Formally, a priority filing is derived from Paris Convention (1883) priority right application (de Rassenfosse et al., 2013). In this paper, we use "filing" and "application" interchangeably.

${ }^{4}$ More complex patent family structures may contain divisionals and continuations. See van Zeebroeck \& van Pottelsberghe (2011) and Dechezleprêtre et al. (2017) for reviews.

${ }^{5}$ Although the requirements for acquiring a UM are less stringent, UMs are not necessarily "weaker" IPRs than patents. In fact, due to the lower inventive step requirement, UMs can be even more difficult to invalidate than patents (see Björkwall 2009). Moreover, in some countries, for instance Germany, the inventive step for UMs and patents has been set at the same level.
} 
administrative and renewal fees. Not all countries have the UM option, but when it exists, technical inventions can be protected with either patents or UMs or, in some countries, even by both (e.g., Germany).

Since Putnam's (1996) seminal work, the size of a patent family has been frequently used as a proxy for the value of a patented invention (Lanjouw et al. 1998; Harhoff et al. 2003; Lanjouw and Schankerman 2004; Reitzig 2004; van Pottelsberghe and van Zeebroeck 2008; Harhoff and Wagner 2009; Frietsch et al. 2010; van Zeebroeck 2011; van Zeebroeck and van Pottelsberghe 2011; Squicciarini et al. 2013). The underlying logic is that the more valuable the invention, the greater the expected returns net of filing costs. Since filing costs increase with the number of jurisdictions where patent protection is sought, expected returns for multi-jurisdictional inventions should also be higher, on average. While the size of a patent family is a well-known indicator of an invention's value, the internal structures of patent families have received little attention until recently (Stevnsborg and van Pottelsberghe 2007; Martínez 2011; Dechezleprêtre et al. 2017; Cao 2015; Cao et al. 2016).

In principle, patent families can contain a variety of patent documents (i.e., territorial exclusive rights) with heterogeneous scopes of protection and economic value. Due to differences in national patent laws, stringency of patent examination processes, and incentives of patent examiners, it is possible that some of the national patent applications filed to protect the same invention are granted by national patent offices whereas some are rejected (Webster et al. 2007; Picard and van Pottelsberghe 2013; Webster et al. 2014; de Rassenfosse et al. 2016). The structure of patent families and the chosen filing routes are of interest because they convey information on the (expected) technological and economic value of the underlying invention and its derivative intellectual property rights (cf. Reitzig 2004; Dernis and Khan 2004; Frietsch and Schmoch 2010; van Zeebroeck and van Pottelsberghe 2011; Frietsch et al. 2013; Cao 2015; Dechezleprêtre et al. 2017).

This study contributes to the scarce literature on patent family structures (Martínez 2011; Cao 2015; Cao et al. 2016; Dechezleprêtre et al. 2017) by incorporating qualitative information on type of IP protection of patent family members, alongside measures of patent family size and structure. Research in this direction might shed light on the effect of UM protection on innovation, the motivations and filing strategies of patent system users, the interplay between patentees and the institutional design of patent systems, and the desirability of further harmonization in international IP laws. We introduce a typology for classification of patent families with UM members and using an extensive patent family data from European countries explore whether there exist systematic patterns in the use of UMs within patent families and in international patenting. We also analyze whether there are quality, filing lag and grant lag differences between European Patent Office (EPO) patent filings with UM and patent priorities. ${ }^{6}$ The findings of this paper indicate that UM members in patent families may be a complementary invention value indicator.

It is particularly important to study these questions in the European context since efficient harmonization of intellectual property rights systems within the European Single Market requires that we understand the functioning and interaction of current patent and UM institutions. Despite some commonalities, UM systems in European countries are

${ }^{6}$ For the sake of consistency, we refer to patents filed at the EPO as "EPO patents" or "EPO filings" throughout the paper. In other studies, they have been referred to as "European patents" (see e.g., Guellec \& van Pottelsberghe 2007; van Zeebroeck 2008). 
heterogeneous (European Commission 1995; Janis 1999; Suthersanen 2006; Prud'homme 2014; Radauer et al. 2015; Heikkilä 2017; Heikkilä and Lorenz 2018). In March 2000, the European Commission suspended the proposal of a "community utility model" (European Commission 1995) - that is, a UM protection system for the entire European Union (EU), due to difficulty in reaching agreement on its form and implementation and also because EU member states wanted to focus on developing the Community patent (European Commission 2002). Thus, questions of the harmonization of national UM systems across EU member states and of the desirability of multi-tier patent protection remain relevant.

The paper is structured as follows. In section 2, we briefly review the literature on patent families. In that section, we also introduce a simple typology of patent families with UM members and present a descriptive analysis of filing patterns in EU member countries. In section 3, we propose a set of hypotheses on the implications of using UMs as priority filings of subsequent EPO filings and analyze whether UM priorities convey information about the quality of the underlying inventions. Section 4 concludes and discusses avenues for future research.

\section{Patent families with utility model members}

In this section, a simple typology for classification of patent families with UM members is introduced. We analyze the filing patterns at national patent offices of EU countries using this typology.

\subsection{Patent family structures and patent filing routes}

Generally, a patent family consists of one or multiple priorities (de Rassenfosse et al. 2013) ${ }^{7}$ and no or multiple subsequent filings (Martínez 2011). According to the Patent Statistics Manual published by the Organisation for Economic Cooperation and Development (OECD), a patent family consists of a "set of patents (or applications) filed in several countries which are related to each other by one or several common priority filings" (OECD 2009, p. 71, as cited in Martínez 2011). However, there exist several different specifications of patent families and the measured sizes of patent families differ accordingly (Martínez 2010, 2011).

Seminal studies using patent family information utilized the patent information database of Derwent Ltd. (e.g., Putnam 1996; Harhoff et al. 2003; Lanjouw and Schankerman 2004). The EPO has produced the Worldwide Patent Statistical Database (PATSTAT) since 2006. It contains information on priority linkages, and since 2008, it has included ready-made tables on patent families (Martínez 2011). Current versions of PATSTAT provide data on two types of patent families: extended patent families (INPADOC), which include both published patent documents and unpublished priorities

${ }^{7}$ Multiple priorities arise when a subsequent patent application claims more than one priority filing. 
claimed in them as family members, and patent families (DOCDB) ${ }^{8}$, which include published patent documents as members (Martínez 2011; European Patent Office 2016).

In addition to INPADOC and DOCDB patent family definitions, triadic patent families - that is, patents that are granted in the U.S. (USPTO) and for which patent applications are filed in both the EPO and the Japanese Patent Office (JPO) to protect the same invention (Dernis and Khan 2004; Sternitzke 2009a; Sternitzke 2009b) - have been used as indicators of inventive activity that are comparable across countries (Frietsch et al. 2010; de Rassenfosse et al. 2013). By definition, triadic patent families have three or more member documents. Also other kinds of patent family definitions have been suggested to compare patenting at the country level, for instance, "transnational patents", which are patent families that include EPO or PCT applications (Frietsch and Schmoch 2010). De Rassenfosse et al. (2013) introduced the count of priority patent applications filed by a country's inventors as an alternative indicator of inventive activity.

Generally, the filing date of a priority filing is the point in time from which the maximum duration of patent protection is counted. It is common practice among patent applicants to file the first patent application at the domestic ${ }^{9}$ patent office and then continue to international protection routes, such as the EPO and the PCT (Dernis and Khan 2004; Frietsch et al. 2013; de Rassenfosse et al. 2013; Dechezleprêtre et al. 2017). The patent application processes of national offices differ from each other (Webster et al., 2007; de Saint-Georges and van Pottelsberghe 2011; Webster et al. 2014; Dechezleprêtre et al. 2017) and some patent offices provide a menu of different types of patents for applicants (Heikkilä and Verba 2017; Heikkilä 2017; Heikkilä and Lorenz 2018). Thus, several strategic choices related to priority filings are available that, among other things, affect the timing of patent protection and the timing of invention disclosure (Johnson and Popp 2003). The choice between patent and UM applications is one of these. Cao (2015) and Cao et al. (2016) showed that Chinese applicants wishing to obtain fast patent protection in the U.S. are likely to choose Chinese UMs instead of patents as priority filings.

Radauer et al. (2015) was among the first to shed light on the role of European UMs in patent families. They report that, in the period 2009-2011, 29\% of DOCDB patent families in the PATSTAT database had at least one UM member. However, when the sample was limited to patent families with multiple members, only $3.4 \%$ contained UM members. This indicates that UMs tend to occur in patent families containing few member documents and cover a limited geographic area - the scope of the sought protection tends to be national rather than international.

\subsection{Typology of patent families with utility model members}

A number of motivations can underlie applicant choice to utilize UMs in their filing strategy. Cash-constrained and entry-level inventors can use UMs to save on costs. Experienced inventors can use the UM option to cope with filing lags in regular patent processing and, in some jurisdictions such as Germany, to fill gaps in enforceability for

\footnotetext{
${ }^{8}$ According to the EPO (2016), when patent or utility model documents share a common DOCDB family identifier, this indicates that "most probably the applications share exactly the same priorities (Paris Convention or technical relation or others)".

${ }^{9}$ Following the common terminology of patent literature, "domestic patent office", in this context, refers to the national patent office in the applicant's country of residence (see e.g., Webster et al. 2014).
} 
pending patent applications (branching-off a UM from a patent application, see Radauer et al. 2015). Other patent system users can use UMs to create an extra layer of uncertainty about the scope of patent protection. The utility model can also serve as a fall-back option after a patent application stalls or is rejected. While we cannot gauge motivations behind filing strategies of patent system users at a very fine-grained level, we can infer some related information from the structure of patent families.

At the country (or patent office) level, all patent families that include at least one UM filing at that country's patent office can be assigned to three mutually exclusive categories. The categories are as follows:

- Category 1, National patent family (single-country patent family): This category refers to patent families in which all patent and UM filings are filed at the same national patent office. ${ }^{10}$

- Category 2, Priority of international patent family (multi-jurisdiction patent family with UM as priority): This category refers to those patent families in which a national priority UM filing is followed by any subsequent filing at any other patent office.

- Category 3, Subsequent filing of international patent family (multi-jurisdiction patent family with UM as subsequent filing): This category consists of those patent families in which a national UM filing is a subsequent filing of any priority filing at any other patent office.

Figure 1 illustrates the classification procedure that generates the three categories. In this simple typology, no difference is made between national patent families in which a $\mathrm{UM}$ is a priority filing and national patent families in which a UM is a subsequent filing. If an international patent family has both a national priority UM filing and a subsequent national UM filing then it is classified as "priority of international patent family" instead of "subsequent filing of international patent family".

10 All singleton UMs are classified as national patent families. Generally, "a singleton" refers to a patent family with exactly one member (i.e., one filing; see Martínez, 2010, 2011; de Rassenfosse et al., 2013). 


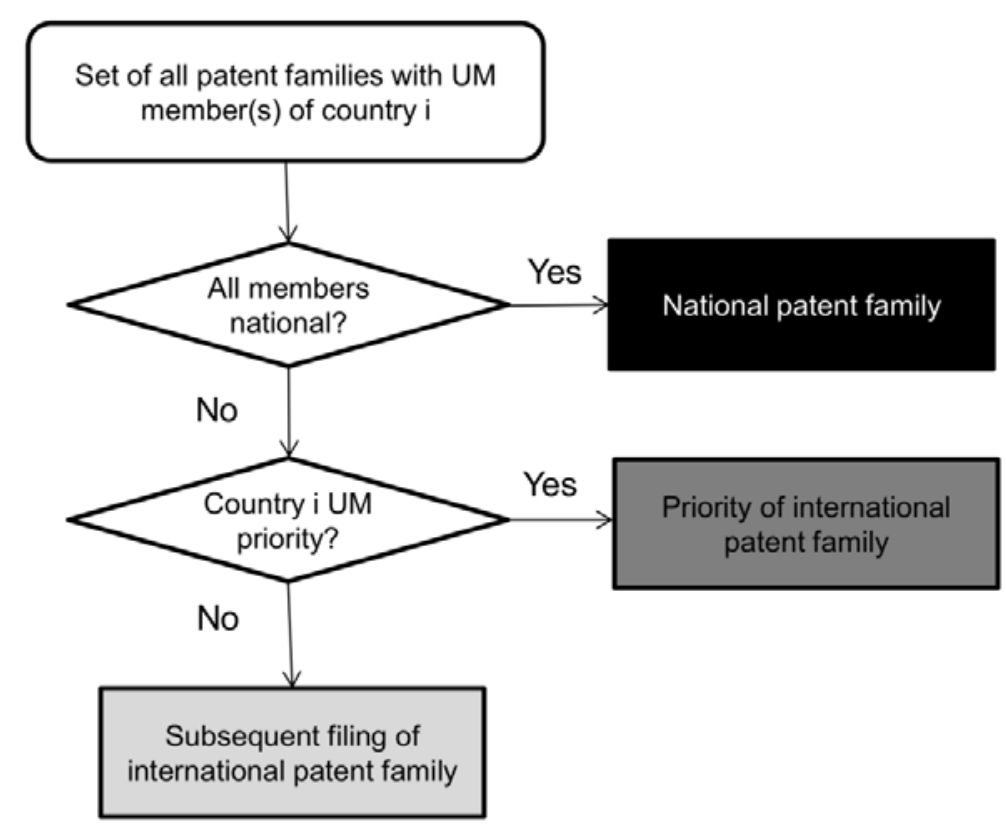

Fig. 1 Classification of patent families with UM members. Complex patent family structures (i.e., patent families with several priority filings; see Martínez 2011) are excluded.

For each category, it is possible to speculate, what it represents or signals and what can be inferred about possible motivations of applicants. In category 1, UMs are used to protect inventions within the national market and probably represent more marginal inventions or, if capital market imperfections are at play, filings from cash-constrained applicants. In category 2, UMs are used as priority filings of international patent families probably to obtain quick protection or as cheap first filings for inventions with uncertain market potential. In category 3, UMs are used to expand the geographic scope of IP protection potentially to include markets marginal to the applicant. Obviously, not all patent families with UM members are similar. The core idea of this simple typology is to facilitate more rigorous analysis and "apples to apples" comparisons between patents, UMs and patent families. The premise that UMs are mainly a protection method for incremental inventions (European Commission, 1995; Janis 1999; Johnson 2002; Beneito 2006; Suthersanen 2006 Kim et al. 2012; Hamdan-Livramento and Raffo 2016) can be questioned if it is observed that UMs are used as part of international patent filing strategies.

A natural way to enrich the typology would be to add legal status (e.g., whether the patent and/or UM members of a patent family are granted/registered ${ }^{11}$ or not, whether renewal fees are paid, whether they are withdrawn or objected, etc.) to the categorization. Such additional dimensions would arguably provide a more detailed picture of the internal workings of patent families and of patent applicants' choices. However, in this

\footnotetext{
11 In most jurisdictions, UMs are automatically registered whereas in other jurisdictions they are examined (e.g., Poland) and there is a possibility that they are rejected (Radauer et al. 2015). Also, if the validity of a UM is challenged in court, there are national differences in the process. For instance, in Germany the burden of proof is on the owner of the UM to show that the claims are valid (Cremers et al. 2017).
} 
paper, we explicitly focus on simple patent family structures and filing routes and leave the analysis of legal status evolution for future research.

\subsection{Data}

The data are extracted from the EPO's PATSTAT database (2016 April edition). We use the readily available DOCDB simple patent family definition in the analysis of patent family structures (European Patent Office 2016). The time window of our data is 2000-2010.12 We base our analysis on two data sets. First, in section 2.4, we focus on patent families, which contain patents or UMs filed at patent offices of EU member states with UM systems. The advantage of restricting the sample to EU member states is that they have a common European institutional framework and some degree of harmonization in IP, at least as far as patents are concerned. ${ }^{13}$ Second, in section 3, we limit the analysis to a subset of the patent families in section 2.4. We focus on EPO patent families which have a UM or a patent priority filing filed at any national patent office of a EU member state with a UM system. ${ }^{14}$ Table 1 lists the sample countries, their accession years to the EU and European Patent Convention and the years when each of the sample countries launched their UM systems.

\footnotetext{
12 In PATSTAT, patent filings for more recent years are available, but the patent family structures of several priority filings filed after 2010 are still subject to changes due to secrecy periods, patent pendency times, etc.

${ }_{13}$ Despite harmonization efforts, there still remain significant differences between EU member states. For instance, pending patents can be enforced in some countries, but not in others. These differences certainly affect the lucrativeness of UMs relative to patents and offer an interesting topic for future research.

14 We exclude from the analysis countries with short-term patent systems (Belgium, Croatia, Ireland, the Netherlands and Slovenia). Although short-term patents are de facto second tier patent systems (likewise UMs) in relation to standard patents, in PATSTAT data, they are not distinguished from normal patents (see de Rassenfosse et al. 2013; Heikkilä 2017; Heikkilä \& Verba 2017).
} 
Table 1 EU member countries with UM systems

\begin{tabular}{lccr}
\hline & EU & EPO & UM system \\
\hline Austria & 1995 & 1979 & 1994 \\
Bulgaria & 2007 & 2002 & 1993 \\
Czech Republic & 2004 & 2002 & 1992 \\
Denmark & 1973 & 1990 & 1993 \\
Estonia & 2004 & 2002 & 1994 \\
Finland & 1995 & 1996 & 1992 \\
France & 1952 & 1977 & 1968 \\
Germany & 1952 & 1977 & 1891 \\
Greece & 1981 & 1986 & 1988 \\
Hungary & 2004 & 2003 & 1992 \\
Italy & 1952 & 1978 & 1934 \\
Poland & 2004 & 2004 & 1924 \\
Portugal & 1986 & 1992 & 1940 \\
Romania & 2007 & 2003 & 2008 \\
Slovakia & 2004 & 2002 & 1992 \\
Spain & 1986 & 1986 & 1929 \\
\hline
\end{tabular}

Notes: Information gathered from official websites of the EPO, EU and WIPO.

A patent family consisting of several filings typically contains members with different filing dates. Therefore, when analyzing the filing trends of patent families with UM members, a choice must be made whether the patent family is classified according to 1) the filing date of the first priority or 2) the filing date of the UM member or some other patent family member. In the next section (2.4), we classify patent families by the filing date of the UM member. In section 3, we compare EPO patent families with patent and UM priority filings and classify them according to the filing date of the EPO application.

Figure 2 shows the share of UMs of total patent and UM filings at national patent offices. Clearly, the relative importance between UMs and patents varies remarkably across countries. ${ }^{15}$ For instance, more than half of all national filings in 2010 were UM filings in Czech Republic, Slovakia and Estonia, whereas in Greece, France and Romania UM filing activity was marginal relative to patent filings.

\footnotetext{
${ }^{15}$ Figure A.1 in the online appendix displays the trends in the aggregate number of UM filings between
} 2000 and 2010. It also demonstrates significant differences in trends between national patent offices. 

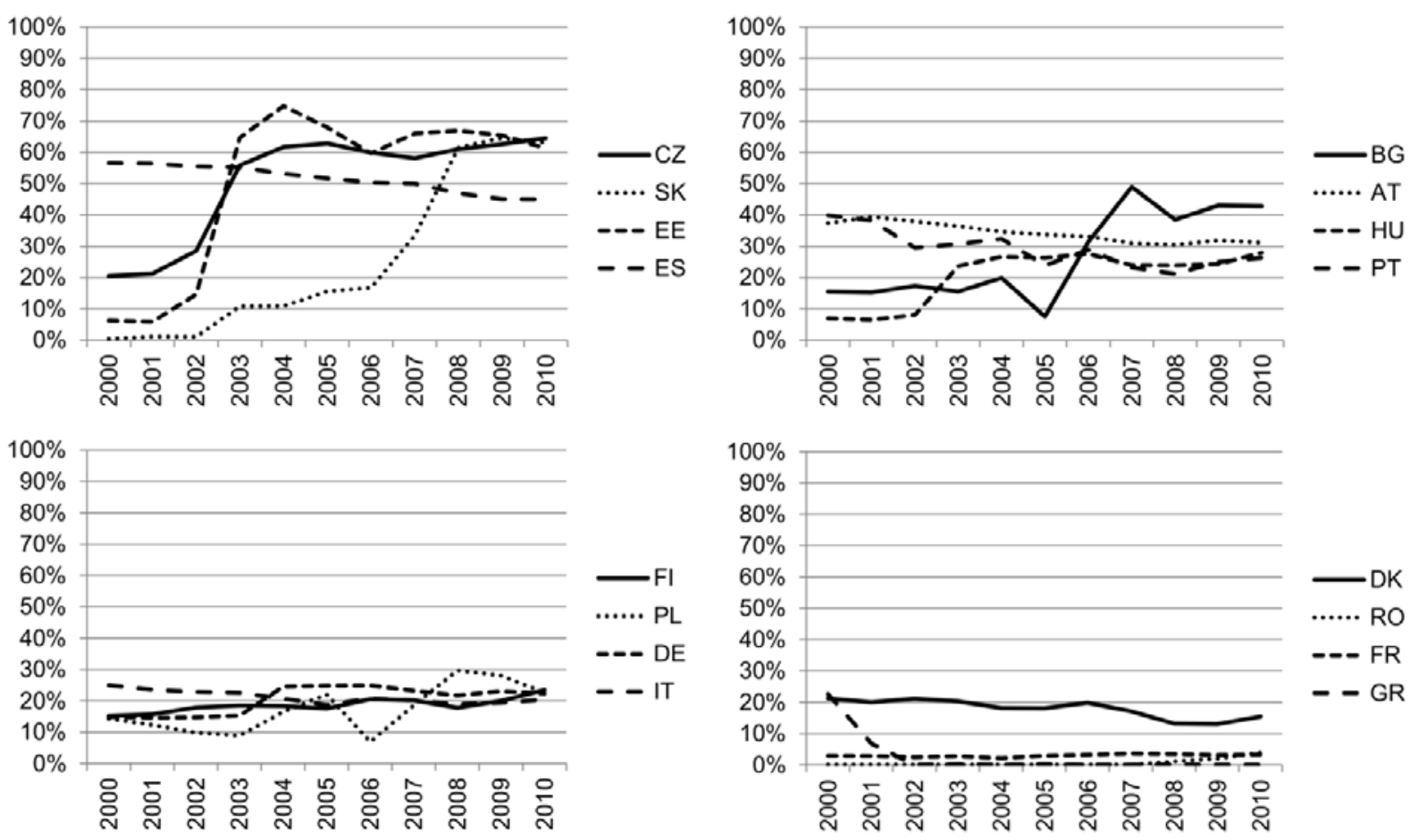

Fig. 2 Share of UM filings of all national filings (patents and UMs). Authors' calculations using PATSTAT 2016 April edition.

\subsection{Descriptive findings}

In this section, we first look at general trends in DOCDB patent families with UM members. Second, we briefly explore singleton patent and UM filing activity. Third, we investigate the role and frequency of UM filings in international and "transnational" (Frietsch and Schmoch 2010) patent filing strategies.

\subsubsection{Filing trends in European countries}

Figure 3 presents, at the country level, the shares of patent family categories for the period 2000-2010, using the typology that we introduced in section 2.2 (Figure 1). In the figure, black bars refer to national patent families, light grey bars to priorities of international patent families, and dark grey bars to subsequent filings of international patent families. The predominance of black bars indicates that UMs are, to a large extent, used to protect inventions for which no protection is sought abroad. This observation is largely in line with earlier empirical and anecdotal evidence (Radauer et al. 2015). However, the data also shows that the use of UMs to protect marginal inventions in a limited geographic domain is only part of the story. Figure 3 also evidences use of UMs as part of more complex international filing strategies (light and dark grey bars). International use of UM filings is particularly prevalent in certain countries: Austria, Germany and Italy - and to a lesser extent in Spain and Portugal. The larger point, suggested by the data, is that perhaps the image of a UM as a signal of a minor invention is an oversimplification. Applicants exhibit a mixture of uses for the UM and there exists a subset of UM filings linked to 
inventions that are important enough to pass the threshold for patent protection. An indepth analysis of the underlying reasons and motives behind national patterns would shed additional light on the differentiated uses of UMs within national contexts. Such analysis would require detailed information on the evolution of national legal and institutional environments and is out of the scope of this study.
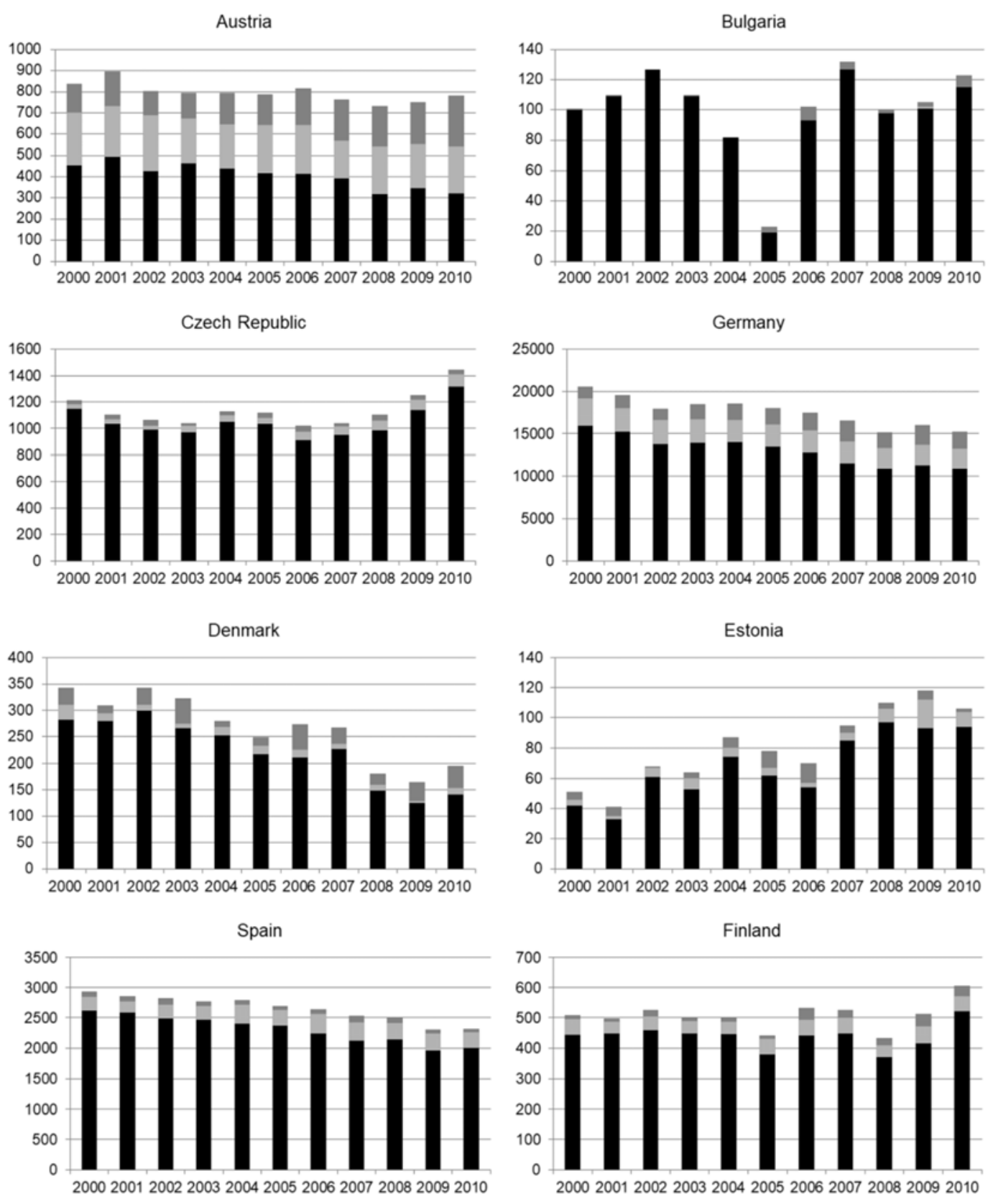

Fig. 3 Patent families with UM filings according to typology, 2000-2010. Black: national patent family; Light grey: priority of international patent family; Dark grey: subsequent filing of international patent family. 
France

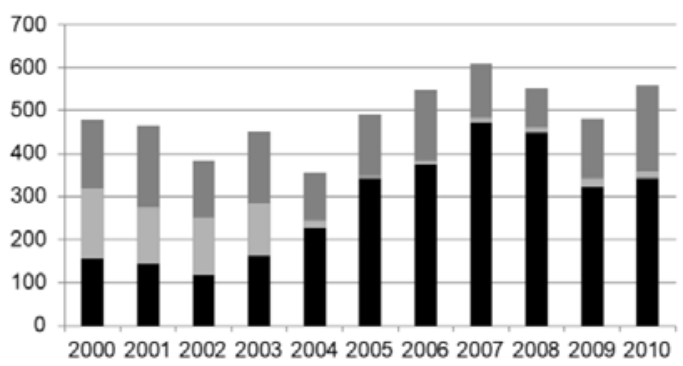

Hungary

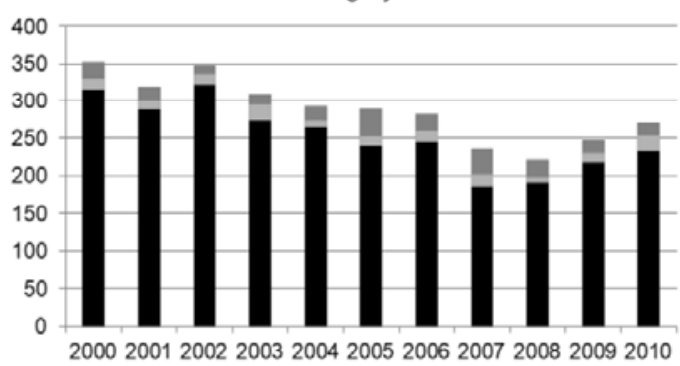

Poland

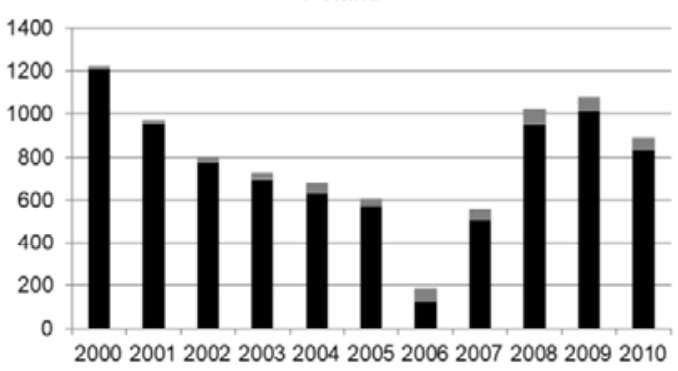

Romania

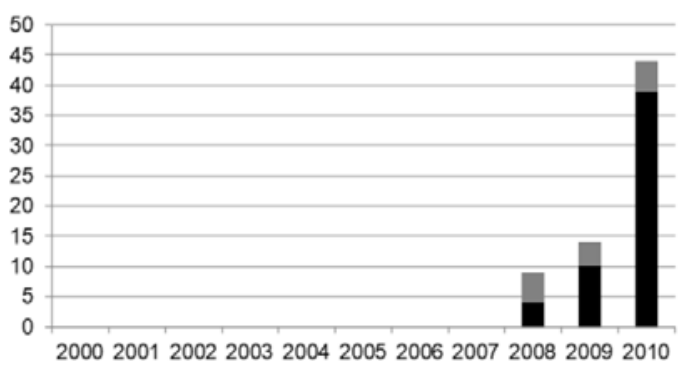

Greece

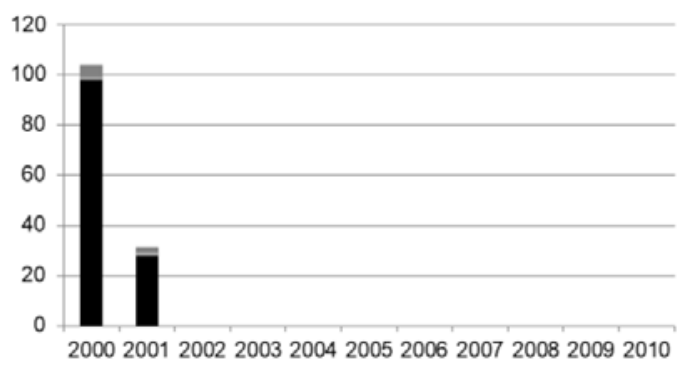

Italy

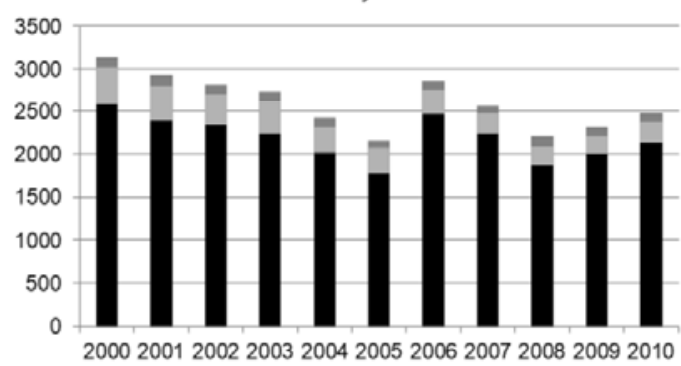

Portugal

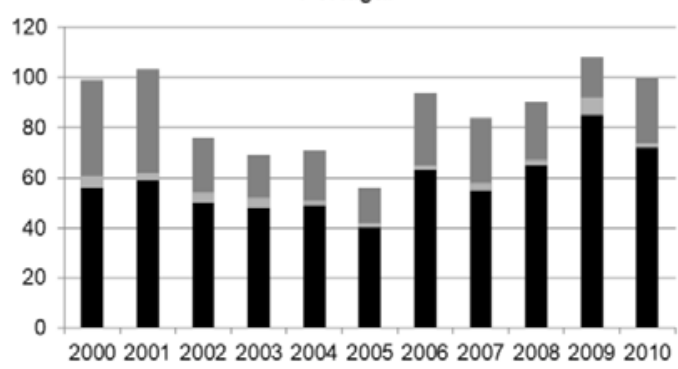

Slovakia

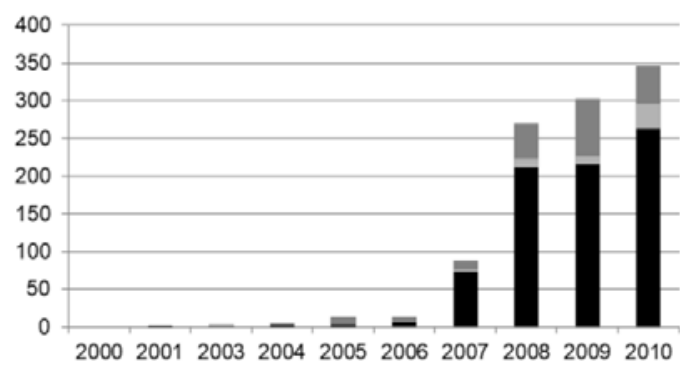

Fig. 3 (continued)

\subsubsection{National and singleton patent families}

If most European UMs are used solely for national protection (see Figure 3; Radauer et al. 2015), it is of interest to ask how common their use is relative to patent singleton filings, which are an alternative way of protecting technical inventions nationally (Heikkilä and Verba 2017). Table 2 compares the average annual levels of UM and patent singleton filings across sample countries between 2000 and 2010. On average, $40 \%$ of all singleton filings during the period were UM singletons. The high shares of UM singletons indicate 
that UMs play an important role in European patent systems. However, there is considerable heterogeneity between countries; the share of UMs in all singleton filings ranges from a few percentages (Romania, France) to more than 60\% (the Czech Republic, Denmark, Estonia, Spain and Slovakia). Prominent heterogeneity suggests that countryspecific institutional differences affect the relative importance of, and substitution between, patents and UMs. These observations have implications for the broader literature utilizing patent-based indicators. For example, the calculation of patenting propensities for industries might require inclusion of UMs in countries with a large share of UMs in total filings.

Table 2 Patent and UM singletons

\begin{tabular}{lcccc}
\hline Patent office & Filing years & $\begin{array}{c}\text { Average number of } \\
\text { singleton filings per year }\end{array}$ & $\begin{array}{c}\text { Share of UM singletons } \\
\text { of all singletons }\end{array}$ \\
\hline Austria & $2000-2010$ & 397 & 394 & $49.8 \%$ \\
Belgium & $2000-2010$ & 111 & 98 & $47.0 \%$ \\
Czech Republic & $2000-2010$ & 502 & 1042 & $67.5 \%$ \\
Denmark & $2000-2010$ & 135 & 214 & $61.4 \%$ \\
Estonia & $2000-2010$ & 20 & 67 & $77.4 \%$ \\
Finland & $2000-2010$ & 970 & 419 & $30.2 \%$ \\
France & $2000-2010$ & 5320 & 273 & $4.9 \%$ \\
Germany & $2000-2010$ & 20725 & 11935 & $36.5 \%$ \\
Greece & $2000-2001$ & 299 & 63 & $21.1 \%$ \\
Hungary & $2000-2010$ & 667 & 241 & $26.5 \%$ \\
Italy & $2000-2010$ & 5629 & 2180 & $27.9 \%$ \\
Poland & $2000-2010$ & 2151 & 750 & $25.9 \%$ \\
Portugal & $2000-2010$ & 120 & 57 & $32.0 \%$ \\
Romania & $2008-2010$ & 712 & 18 & $2.4 \%$ \\
Slovakia & $2008-2010$ & 123 & 230 & $65.2 \%$ \\
Spain & $2000-2010$ & 1257 & 2305 & $64.7 \%$ \\
\hline
\end{tabular}

Notes: For Greece, there is no data on national UM filings after 2001 in the PATSTAT database (April 2016 edition). Romania introduced its UM system in 2008. For Slovakia, the numbers are reported for only 2008-2010 due to missing data.

The literature on pre-emptive patenting suggests that incumbents apply for patents in order to pre-empt or block others from protecting the invention (Gilbert and Newbery 1982; Guellec et al. 2012). Another related strand of literature discusses defensive publishing - that is, agents intentionally publish the results of their R\&D projects in order to destroy the novelty and, thus, prevent competitors from patenting (e.g., Henkel and Lernbecher 2008; Hall et al. 2014). Filing patents and later withdrawing them may be preferred to other forms of defensive publishing since a published patent application "leaves a paper trail" with a verifiable date of publication and could be easily found by patent examiners who examine the novelty of inventions (Guellec et al. 2012). Given their 
attributes, UMs may be a preferred mechanism for defensive patenting. Therefore, an interesting question for future research is how pervasive is the use of UM filings to preempt competitors from patenting?

\subsubsection{International filing strategies}

The communicated raison d'être for several European UM systems is that they provide fast, simple and cheap protection, and that they are especially designed for small and mediumsized enterprises and individual inventors (see European Commission 1995; Suthersanen 2006; Prud'homme 2014; Radauer et al. 2015; Heikkilä 2017; Heikkilä and Lorenz 2018). However, systematic use of UMs as part of international patent filing strategies would signal that they may also play a strategic role for other users of the patent system. Next, we analyze this possibility by exploring how frequently UMs are used as a part of international patent filing strategies. We first consider the filing activity and links between patent offices for every EU member state with a UM system separately. Second, we analyze transnational patent filings with UM members.

Filing activity and links between filing offices: Tables A.1-A.13 in the online appendix (Electronic Supplementary Material) report the ranking of the most frequent links (i.e., dyads) separately for every EU member state with a UM system over the period 2000-2010. The sample consists of patent families for which priority filings were filed between 2000 and 2010.16 Moreover, only those subsequent filings, which were filed during the same period, are counted. For every patent office, the dyads are reported separately for national patent and UM priorities and patent and UM subsequent filings to enable comparisons between patents and UMs.

A few interesting observations emerge: First, in several countries, the role of UMs is quite limited in international filings, and there are only a few dozen links between priority or subsequent UM filings and foreign patent offices (as Figure 3 already demonstrated). Second, the rankings of priority and subsequent filing countries are relatively similar between patents and UMs. Third, for the largest EU member states with UM systems (Germany, Italy and Spain), the most frequent subsequent filing office for UM priority filings is the EPO. Fourth and finally, national UM filings are relatively often used as priority filings for subsequent PCT filings at WIPO. The last two observations are in line with observations made by Radauer et al. (2015) and indicate that UMs provide some strategic advantages as priority filings of international patent families.

Transnational patent filings with UM members: WIPO's PCT and the European Patent Convention are "supranational procedures" that have facilitated multinational patent filing strategies (Martínez 2011). The PCT system is designed to assist applicants in seeking international patent protection. ${ }^{17}$ A PCT filing is not an actual patent application

\footnotetext{
16 Greece, Bulgaria and Romania had few observations (less than 10 international patent families with national UM members) and their figures are not reported. Moreover, Tables A.1-A.13 report only links or dyads for which there are 10 or more observations.

${ }_{17}$ According to WIPO (2008, p. 277): “The principal objective of the PCT is, by simplification leading to more effectiveness and economy, to improve on - in the interests of the users of the patent system and the Offices which have responsibility for administering it - the previously established means of applying in several countries for patent protection for inventions." The PCT process provides applicants with a longer period in which to decide whether to apply for national patents. Instead of the standard 12 months (Paris Convention priority year), with a PCT filing the "international phase" that is, the time limit to enter the national or regional phase - is 30-31 months depending on the
} 
but a way to maintain the option to file patent applications abroad in the future (Guellec and van Pottelsberghe 2007; WIPO 2008; Dechezleprêtre et al. 2017). At the EPO, it is possible to file a patent application and, upon grant, validate the patent in desired EPO member states by paying national renewal fees (van Pottelsberghe and van Zeebroeck 2008). Thus, a validated EPO patent, is in practice, a bundle of national patents. "Euro-

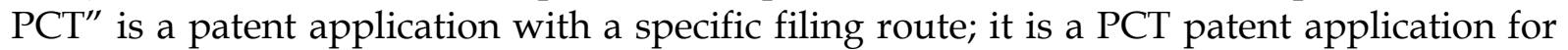
which the EPO is designated as the International Search Authority (ISA) (Guellec and van Pottelsberghe 2002; Guellec and van Pottelsberghe 2007; Frietsch et al. 2013). Euro-PCT filings are indicated in Tables A.1-A.13 as EPO (PCT). Frietsch and Schmoch (2010) suggested the number of "transnational patents" - that is, patent families with at least one EPO filing or PCT filing - as an innovation indicator that is comparable across countries. Interestingly, tables A.1-A.13 in the online appendix (Electronic Supplementary Material) show that UM filings are relatively often used as priority filings for subsequent PCT filings and EPO filings. In other words, UMs are claimed as priority filings for transnational patents. This finding is at odds with the conventional view associating UMs with incremental inventions.

According to Sternitzke (2009a), applicants wishing to achieve fast patent protection in Europe should file a PCT application and choose the EPO as the international examination author. Frietsch et al. (2013) have documented that this Euro-PCT route is the most popular route for filing for patent protection at the EPO: it is more popular than direct EPO filing or the use of national filing as priorities for subsequent EPO filings. Radauer et al. (2015) pointed out, on the basis of qualitative feedback from IP professionals, that UMs can be used as priority filings for subsequent PCT applications to provide national protection during the application phase. Moreover, IP professionals noted that UMs are feasible solutions when an invention is initially considered to be of low importance but is later found to be significant; in this case, they can be used as priorities for PCT filings (Radauer et al. 2015).

Table 3 documents how frequently UMs from sample countries are members of transnational patent families (as either priority or subsequent filings). "EPO" indicates a patent family that contains an EPO filing, and "PCT" indicates that the patent family contains a PCT filing. These categories are overlapping as the patent family can simultaneously have a PCT filing and a filing at the EPO. "Euro-PCT" is a patent family in which the EPO is the receiving office of the PCT filing. Table 3 shows that, over the period 2000-2010, UM priorities in transnational patent families from 16 sample countries were most often used as priorities for subsequent EPO filings. German, Austrian and Italian UMs were most often members of Euro-PCT filings while, in other countries, the use of UMs as members of Euro-PCT families was negligible. A more detailed analysis of the use of UMs in EPO and PCT patent families is out the scope of this study and is left for future research.

subsequent filing office (Sternitzke 2009a). Due to this additional time, inventions with unclear market potential are likely candidates for using the PCT route (Guellec \& van Pottelsberghe 2000; Guellec \& van Pottelsberghe 2002; Sternitzke 2009a; Dechezleprêtre et al. 2017). 
Table 3 Transnational patent families with UM members, 2000-2010

\begin{tabular}{lrrrr}
\hline $\begin{array}{l}\text { Patent office at which } \\
\text { UM member of patent } \\
\text { family is filed }\end{array}$ & EPO & PCT & Euro-PCT & $\begin{array}{c}\text { Transnational } \\
\text { patents }\end{array}$ \\
\hline Germany & 21474 & 10185 & 6847 & 22777 \\
Italy & 2283 & 878 & 313 & 2582 \\
Austria & 1385 & 854 & 630 & 1609 \\
Spain & 413 & 196 & 22 & 461 \\
Finland & 193 & 211 & 13 & 290 \\
Czech Republic & 142 & 216 & 13 & 271 \\
Denmark & 133 & 130 & 14 & 173 \\
Hungary & 60 & 136 & 8 & 152 \\
France & 84 & 72 & 10 & 109 \\
Poland & 48 & 58 & 15 & 77 \\
Estonia & 29 & 47 & 8 & 57 \\
Portugal & 22 & 28 & 4 & 40 \\
Slovakia & 18 & 28 & 5 & 36 \\
Bulgaria & 3 & 5 & 0 & 6 \\
Greece & 2 & 0 & 0 & 2 \\
Romania & 1 & 1 & 0 & 1 \\
& 26290 & 13045 & 7902 & 28643 \\
\hline
\end{tabular}

Notes: First column indicates the country in which the UM member of international patent family was filed during the 2000-2010 period. The categories are not mutually exclusive; EPO and PCT filings may overlap, and Euro-PCT filings are concurrently members of EPO and PCT families by definition. The same patent family can be listed under multiple countries if the family contains UMs in several jurisdictions.

\section{Comparison of EPO filings with patent and UM priorities}

Our descriptive analyses in previous sections showed that it is not exceptional to claim UMs filed at certain European patent offices as priority filings in subsequent EPO filings. However, to our knowledge, the only study that has analyzed the choice between patents and UMs in national patent offices as priority filings for subsequent EPO filing is Cao et al. (2016). ${ }^{18}$ While Cao et al. (2016) focused on Chinese priority patents and UMs, we examine whether there are quality differences between EPO filings with patent and UM priority filings in European patent offices. In this context, "quality" refers to the technological quality or value of the invention subject to patent or UM protection (see Frietsch et al. 2010; van Zeebroeck 2011; Squicciarini et al. 2013). This quality of invention is distinct from the "legal quality" of the patent (Burke and Reitzig 2007; van Pottelsberghe 2011; de

18 The settings of Cao (2015) and Cao et al. (2016) are very similar as they analyze the choice between a Chinese patent and a UM as a priority filing for a subsequent USPTO or EPO filing. 
Saint-Georges and van Pottelsberghe 2011; Picard and van Pottelsberghe 2013) - that, is how well it is drafted and what is the probability of its validity if challenged or enforced in court.

In an international context, when the same invention is protected in several countries, it goes through several screening processes - that is, its quality and patentability is examined at multiple national patent offices by multiple patent examiners. Webster et al. (2014) provide empirical evidence that the national treatment principle is not strictly practiced as domestic applicants are more often granted patents in comparison to foreign applicants. ${ }^{19}$ Also, the stringency of examination between national patent offices has been observed to differ (de Saint-Georges and van Pottelsberghe 2011; van Pottelsberghe 2011). Hence, when comparing the quality of inventions that are protected in several countries, the differences in grant rates and other patent quality measures should be interpreted with caution. In order to enable quality comparison, we focus on patent families, which contain an EPO filing claiming a priority filing in some of our sample countries, and examine the differences between EPO filings with patent priority and UM priority filings. The focus on EPO filings guarantees a certain level of comparability between the quality of inventions as they are examined according to similar principles and stringency and are subject to the same patentability requirements (cf. Sapsalis et al. 2006; van Pottelsberghe 2011; Cao 2015; Cao et al. 2016).

\subsection{Testable hypotheses}

UM systems differ across countries and have evolved over time (European Commission 1995; Janis 1999; Suthersanen 2006; Prud'homme 2014; Radauer et al. 2015; Heikkilä 2017; Heikkilä and Lorenz 2018) but common to all of them is that they are considered to be an especially suitable method of protection for incremental technical inventions (Johnson 2002; Beneito 2006; Kim et al. 2012; Hamdan-Livramento and Raffo 2016). Hence, we expect that a larger share of technical inventions with a national UM priority filing and a subsequent EPO application are incremental inventions than of technical inventions with a national patent priority filing and a subsequent EPO application.

\section{Hypothesis 1a:}

EPO filings with UM priorities are, on average, of lower quality than EPO filings with patent priorities.

In a recent study, Dechezleprêtre et al. (2017) provided evidence that the timespan between the first priority filing and the last filing within a patent family (hereafter "timespan" for brevity) is associated with common patent quality measures. They found a statistically significant positive correlation between the timespan of a patent family and the value of the priority patent. Therefore, we complement Hypothesis 1a with an additional hypothesis on the quality of EPO filings:

\footnotetext{
${ }_{19}$ According to WIPO (2008, pp. 242-243), "national treatment means that, as regards the protection of industrial property, each country party to the Paris Convention must grant the same protection to nationals of the other member countries as it grants to its own nationals" and "national treatment rule guarantees not only that foreigners will be protected, but also that they will not be discriminated against in any way".
} 


\section{Hypothesis 1b:}

EPO filings with UM priorities have, on average, a shorter timespan than EPO filings with patent priorities at the same patent office.

Patent pendency times and grant lags - that is, the time elapsed between the application date and grant (or withdrawal or rejection) date of a patent - have been analyzed in previous studies (Johnson and Popp 2003; Palangkaraya et al. 2008; Harhoff and Wagner 2009; Régibeau and Rockett 2011; Liegsalz and Wagner 2013; Cao 2015; Cao et al. 2016). Figure A.2 in the online appendix illustrates the concepts of filing lag, grant lag and timespan. UMs are quicker to obtain than patents and are, therefore, an especially attractive form of IP protection for applicants in need of fast protection (Cao 2015; Radauer et al. 2015; Cao et al. 2016; Heikkilä and Lorenz 2018). Cao (2015) and Cao et al. (2016) analyzed filing lags between Chinese patent and UM priorities and subsequent U.S. filings ("SIPO-USPTO dyads" ${ }^{20}$ ) and found evidence that applicants who favor fast protection in the U.S. choose Chinese UM priority instead of Chinese patent priority. In their case, a filing lag was defined as the time elapsed between the application date of the Chinese priority filing at SIPO and the date of the first subsequent filing at the USPTO. Heikkilä and Lorenz (2018) using German firm-level data, found that having short product and process life cycles is associated with the use of UMs. Therefore, we expect the choice of a UM priority to be associated with shorter filing lags of subsequent EPO applications in comparison to filing lags of EPO application with patent priorities. In this context, filing lag refers to the time elapsed between the priority filing date at a national patent office and the filing date of the subsequent EPO filing date.

\section{Hypothesis 2:}

The average filing lag between priority UMs and subsequent EPO filings is shorter than the average filing lag between priority patents and subsequent EPO filings.

On the other hand, it is possible that the major underlying reason for the choice of priority UM over priority patent is simply cost minimization and, thus, we do not observe a significant difference in EPO filing lags.

Following the same reasoning as for filing lags, we expect the applicants in need of fast protection to prefer fast granting and, therefore, to choose UMs. A pending patent application provides only uncertain conditional protection. Hence, we expect the average grant lag of granted EPO patents with UM priorities to be shorter than the average grant lag of granted EPO patents with patent priorities. Here, the grant lag refers to the time elapsed between the filing data of the EPO filing and the grant date of the EPO filing.

\section{Hypothesis 3:}

The average grant lag of granted EPO patents with UM priorities is shorter than the average grant lag of granted EPO patents with patent priorities.

20 SIPO refers to State Intellectual Property Office of China. 
However, some applicants may choose a UM priority filing due to higher uncertainty about the value of the underlying invention (Radauer et al. 2015). This would probably have an opposite effect on the grant lag difference. Granted EPO filings are a set of inventions that have passed the examination process at the EPO and, thus, satisfy patentability requirements. As the examination process is, in practice, partly a process of negotiation between an applicant and an examiner (Harhoff and Wagner 2009), a high level of uncertainty about the value of the invention might induce the applicant to lengthen negotiations strategically in order to learn more about the value and market potential of the invention.

\subsection{Results}

\subsubsection{Descriptive and graphical analysis}

Our sample consists of EPO patent applications, filed between 2000 and 2010, that are subsequent filings of national patent or UM priorities in any of the sample countries filed during the same period. ${ }^{21}$ The patent families can have no or many subsequent filings in other patent offices in addition to at least one EPO filing claiming the priority. Figure 4 illustrates the particular types of patent family structures on which we focus in our analysis. It should be noted that a large share of EPO filings are direct filings (i.e., they are themselves priority filings at EPO and do not claim priority patents or UMs; see Frietsch et al. 2013), but they are not part of this analysis because such filings bypass national patent systems in the initial phase. ${ }^{22}$

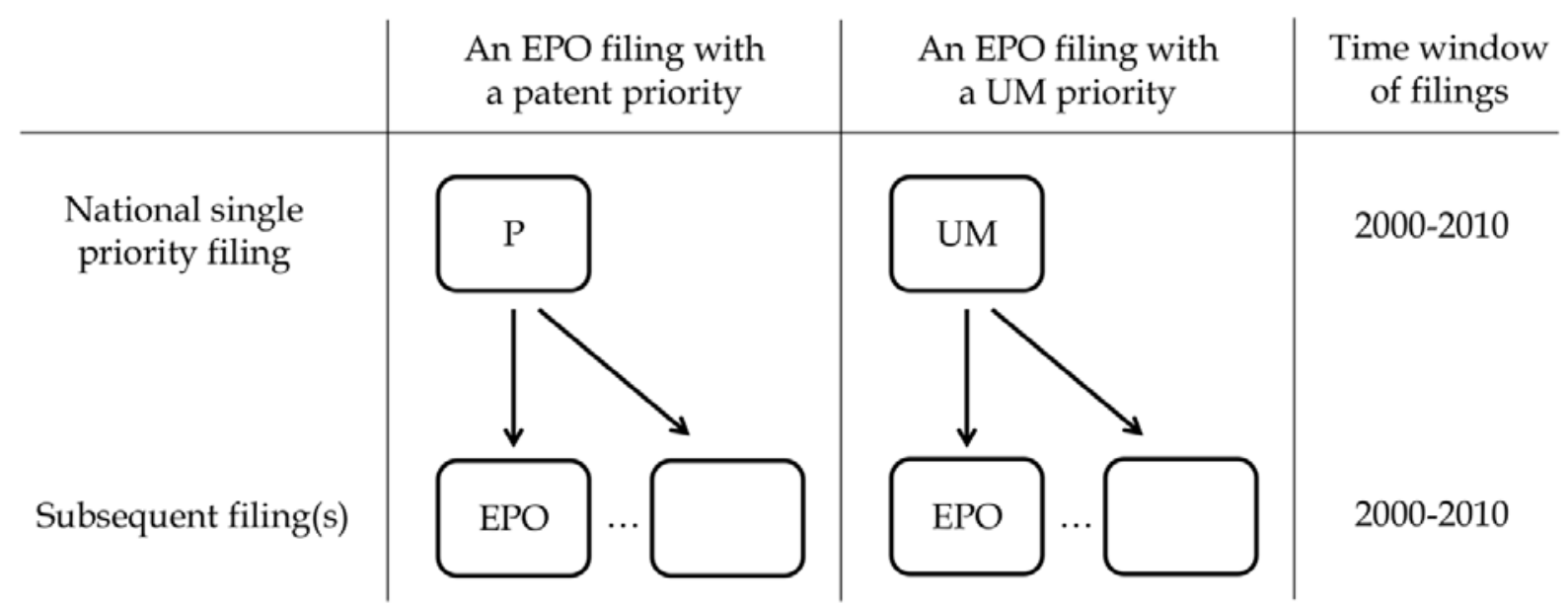

Fig. 4 Patent family structures of interest. Only patent families in which both the priority filing and subsequent EPO filing were filed between 2000 and 2010 are included in the sample.

\footnotetext{
${ }^{21}$ We have limited our attention to this period since several patent quality indicators (grant, citations) and grant lag information are available only several years after the priority filing date.

22 Patent families with complex structures (multiple priorities; see Martinéz 2011) are excluded.
} 
UMs from some European countries are used only in rare occasions as priority filings of subsequent EPO filings (see Tables A.1-A.13 in the Electronic Supplementary Material). Therefore, we exclude from the sample national patent offices with less than $30 \mathrm{UM}$ priorities that are followed by EPO filings during the period (Bulgaria, Estonia, France, Greece, Poland, Portugal, Romania and Slovakia). The final set of countries consist of EPO filings with priorities at the national patent offices of Austria, the Czech Republic, Germany, Denmark, Spain, Finland, Hungary and Italy. During the preliminary analysis of the data, it became clear that, by far, the largest share of patent families in our sample have German UM or patent priority filings (132823/172722 $\approx 77 \%)$. Hence, we report all descriptive statistics and results separately for two samples: Germany and other countries.

We measure the quality of patent families with common invention quality measures: 1) whether the European patent is granted, 2) whether the European patent is cited in future filings, 3) the number of forward citations received, and 4) the patent family (DOCDB) size (Frietsch et al. 2010; van Zeebroeck 2011; Squicciarini et al. 2013). Tables 4 and 5 compare the characteristics of EPO filings with patent and UM priorities. ${ }^{23}$ In addition to common quality measures, we also report the share of individual first applicants, number of inventors, the share of EPO patent families containing PCT filings, the average filing lag between national priorities and subsequent EPO filings, the average grant lags of EPO patents and the average timespan (Dechezleprêtre et al. 2017) between the priority filing and the last subsequent filing.

23 The descriptive statistics for the aggregate data are reported in Table A.14 in the online appendix (Electronic Supplementary Material). 
Table 4 Characteristics of EPO patent applications with patent or UM priorities in countries other than Germany, 2000-2010

\begin{tabular}{|c|c|c|c|c|c|c|}
\hline \multicolumn{7}{|c|}{ Priority filing type } \\
\hline & \multicolumn{2}{|c|}{ Utility model } & \multicolumn{2}{|c|}{ Patent } & \multicolumn{2}{|c|}{ Total } \\
\hline Applications & \multicolumn{2}{|c|}{4153} & \multicolumn{2}{|c|}{35746} & \multicolumn{2}{|c|}{39899} \\
\hline \multirow[t]{2}{*}{ Grants/Registrations } & \multicolumn{2}{|c|}{1746} & \multicolumn{2}{|c|}{17714} & \multicolumn{2}{|c|}{19460} \\
\hline & \multicolumn{2}{|c|}{ Utility model } & \multicolumn{2}{|c|}{ Patent } & & \\
\hline Characteristic & Mean & Std. Dev. & Mean & Std. Dev. & $\begin{array}{c}\text { Difference } \\
\text { in means }\end{array}$ & Std. Err. \\
\hline Granted & 0.420 & 0.494 & 0.496 & 0.500 & $0.075^{\star * *}$ & 0.008 \\
\hline Cited & 0.687 & 0.464 & 0.770 & 0.420 & $0.083^{* * *}$ & 0.007 \\
\hline Number of citations & 2.556 & 4.335 & 4.028 & 6.822 & $1.472^{* * *}$ & 0.108 \\
\hline Patent family size & 4.416 & 3.029 & 5.770 & 4.117 & $1.353^{* * *}$ & 0.066 \\
\hline Timespan & 411.712 & 266.099 & 518.290 & 442.083 & $106.578^{* * *}$ & 7.003 \\
\hline Number of inventors & 1.431 & 0.924 & 1.946 & 1.464 & $0.515^{* * *}$ & 0.023 \\
\hline Individual applicant & 0.242 & 0.428 & 0.150 & 0.357 & $-0.092^{* * *}$ & 0.006 \\
\hline PCT filing & 0.297 & 0.457 & 0.520 & 0.450 & $0.223^{* * *}$ & 0.008 \\
\hline Domestic applicant & 0.928 & 0.258 & 0.900 & 0.301 & $-0.029^{* * *}$ & 0.005 \\
\hline Filing lag & 327.77 & 76.987 & 343.34 & 53.606 & $15.570^{* * *}$ & 0.926 \\
\hline Grant lag & 1498.82 & 669.750 & 1578.36 & 713.740 & $79.540^{* * *}$ & 17.807 \\
\hline
\end{tabular}

Notes: Countries included: Austria, the Czech Republic, Denmark, Spain, Finland, Hungary and Italy. All variables show the statistics for the applications sample (39899 obs.) except grant lag, which is reported for the granted subsample (19460 obs.). ${ }^{* * *}$ indicates statistical significance at a $1 \%$ significance level. 
Table 5 Characteristics of EPO patent applications with patent or UM priorities in Germany, 2000-2010

\begin{tabular}{|c|c|c|c|c|c|c|}
\hline \multicolumn{7}{|c|}{ Priority filing type } \\
\hline & \multicolumn{2}{|c|}{ Utility model } & \multicolumn{2}{|c|}{ Patent } & \multicolumn{2}{|c|}{ Total } \\
\hline Applications & \multicolumn{2}{|c|}{12646} & \multicolumn{2}{|c|}{120177} & \multicolumn{2}{|c|}{132823} \\
\hline \multirow[t]{2}{*}{ Grants/Registrations } & \multicolumn{2}{|c|}{7010} & \multicolumn{2}{|c|}{69072} & \multicolumn{2}{|c|}{76082} \\
\hline & \multicolumn{2}{|c|}{ Utility model } & \multicolumn{2}{|c|}{ Patent } & & \\
\hline Characteristic & Mean & Std. Dev. & Mean & Std. Dev. & $\begin{array}{c}\text { Difference } \\
\text { in means }\end{array}$ & Std. Err. \\
\hline Granted & 0.554 & 0.497 & 0.575 & 0.494 & $0.020^{\star * *}$ & 0.005 \\
\hline Cited & 0.775 & 0.417 & 0.840 & 0.366 & $0.065^{* * *}$ & 0.003 \\
\hline Number of citations & 3.644 & 5.56 & 5.304 & 7.983 & $1.660^{* * *}$ & 0.073 \\
\hline Patent family size & 4.322 & 2.758 & 5.391 & 3.319 & $1.068^{* * *}$ & 0.031 \\
\hline Timespan & 399.92 & 277.91 & 509.13 & 432.71 & $109.203^{* * *}$ & 3.930 \\
\hline Number of inventors & 1.685 & 1.164 & 2.442 & 1.653 & $0.757^{* * *}$ & 0.015 \\
\hline Individual applicant & 0.158 & 0.365 & 0.051 & 0.221 & $-0.106^{\star * *}$ & 0.002 \\
\hline PCT filing & 0.278 & 0.448 & 0.532 & 0.499 & $0.254^{* * *}$ & 0.005 \\
\hline Domestic applicant & 0.863 & 0.344 & 0.893 & 0.309 & $0.031^{* * *}$ & 0.003 \\
\hline Filing lag & 322.26 & 77.485 & 330.61 & 64.916 & $8.350 * * *$ & 0.619 \\
\hline Grant lag & 1478.04 & 675.256 & 1579.58 & 712.491 & $101.536^{* * *}$ & 8.889 \\
\hline
\end{tabular}

Notes: All variables show the statistics for the applications sample (132823 obs.) except grant lag, which is reported for the granted subsample (76082 obs.). ${ }^{* * *}$ indicates statistical significance at a $1 \%$ significance level.

In line with Hypothesis 1a, comparisons between patent and UM priorities in both Tables 4 and 5 reveal that the average quality of inventions (share of granted, share of cited, number of citations, patent family size) with patent priorities is systematically higher than that of UM priorities. The unconditional average quality differences (difference of means column) are, in most cases, more pronounced for the sample consisting of other countries (Table 4) than for Germany (Table 5). In both samples, a larger share of EPO filings with patent priorities belongs to patent families containing PCT filings. This is consistent with earlier studies that have found PCT filings to be positively associated with invention value (e.g., Reitzig 2004; van Zeebroeck and van Pottelsberghe de la Potterie 2011). The share of individual first applicants is statistically significantly higher for UM priorities than for patent priorities while number of inventors is significantly higher for patent priorities. The share of domestic ${ }^{24}$ applicants is over $90 \%$ for both UM and patent priority groups but slightly higher for UM priorities in other countries' sample. Unexpectedly, the share of domestic applicants is statistically significantly higher for the patent priority group in Germany's sample. Consistent with Hypothesis $1 b$, the timespan is found to be longer for patent priorities than for UM priorities in both Table 4 and Table 5. The differences of means are almost equal between samples (ca. 109 days for Germany and ca. 107 days for other countries).

24 These are applicants residing in the same country as the national patent office at which the priority is filed. 
Tables 4 and 5 show that both the average filing lag between the priority and the subsequent EPO filing and the average grant lag of subsequent EPO patents are shorter for patent families with UM priorities than for patent families with patent priorities. This is consistent with the fact that, in most countries, UMs provide faster protection than patents (Cao 2015; Cao et al. 2016; Heikkilä and Lorenz 2018). Thus, comparisons of unconditional means indicate that Hypotheses 2 and 3 are supported.

The distributions of filing lags, grant lags and time spans are reported in Figures A.3-A.5 in the online appendix (Electronic Supplementary Material). No clear differences in lag patterns are evident except in the timespan distributions; both EPO filings with patent and UM priorities show a small peak at approximately 30 months, but the peak is relatively larger for patent priorities. The PCT system's time limit of 30 months to enter the national or regional phase (Sternitzke 2009a; Frietsch et al. 2013) is the most likely reason for these peaks. Tables 4 and 5 reported that a significantly smaller share of EPO patent families with UM priorities include PCT filings (ca. 28-30\%) in comparison to EPO patent families with patent priorities (52-53\%). This is one potential explanation for the difference between timespan distributions (see Figure A.5 in the Electronic Supplementary Material).

Figures 5, 6 and 7 in the appendix report the Kaplan-Meier survivor functions for filings lags, grant lags and timespans, respectively. The survival functions show similar patterns indicating that there are no radical differences in the filing and granting processes between EPO filings with patent and UM priorities. For both Germany and other countries, UMs have systematically smaller survival rates in every period, suggesting that filing lag, grant lags and timespans are consistently shorter for UMs. We test the equality of survival functions with standard log-rank tests (Kalbfleisch and Prentice 2002, pp. 2022). In all cases, log-rank tests reject, at a $1 \%$ significance level, the null hypothesis that survivor functions between EPO filings with patent and UM priorities are equal.

\subsubsection{Regression analysis}

We now move away from consideration of unconditional means to analyze the association between the choice of priority filing (patent or UM) and the subsequent EPO filing's quality, while controlling for patent filing and family-level characteristics. To test Hypothesis 1a we estimate the following regression equation:

$$
\text { Quality }_{\mathrm{ijct}}=\mathrm{a}+\beta_{1} U M_{-} \text {priority }_{\mathrm{i}}+\mathbf{x}_{\mathrm{i}}^{\prime} \gamma+\theta_{\mathrm{j}}+\mu_{\mathrm{c}}+\eta_{\mathrm{t}}+\varepsilon_{\mathrm{ijct}}
$$

where Quality $\mathrm{ijct}_{\mathrm{j}}$ is an invention quality indicator (e.g., indicator for grant, indicator for citation, citation count, patent family size or time span) of patent family $i$ in technological field $j$, priority office $c$ and filing year (of the EPO filing) $t$. Parameter $a$ is a constant. UM_priority $y_{\mathrm{ijct}}$ is a dummy variable: 1 if the priority of patent family $i$ is a UM and 0 if the priority is a patent (see Figure 4). As to the other variables: $\mathbf{x}_{\mathrm{i}}$ is a vector of patent family level controls, $\theta_{\mathrm{j}}$ is a technological field indicator, $\mu_{\mathrm{c}}$ is a priority patent office indicator, which control for country specific characteristics that remain constant over time (e.g., country size), $\eta_{\mathrm{t}}$ is a filing year indicator, and $\varepsilon_{\mathrm{ijct}}$ is a patent family specific error term. Results would support Hypotheses $1 \mathrm{a}$ if the estimate of $\beta_{1}$ is found to be statistically significant and negative.

Table 6 reports the estimation results. Separate models are estimated for different quality indicators. Since, in columns 1-4, the dependent variable is binary ( 1 if the EPO 
patent is granted, 0 otherwise; 1 if the patent family has received forward citations, 0 otherwise), we estimate probit models and report average marginal effects. In columns 58 , the dependent variable is a count variable, and we estimate negative binomial models. Since patent family size is always 1 or larger, we estimate zero-truncated negative binomial models in columns 7 and 8 .

In columns 9 and 10, the dependent variable is timespan - that is, duration between the first filing and the last filing within patent family $i$, and we estimate a Cox proportional hazard $(\mathrm{PH})$ model. ${ }^{25}$ The Cox $\mathrm{PH}$ model can be written as follows: $\mathrm{h}_{\mathrm{i}}(\mathrm{t}, \mathbf{x})=$ $h_{0}(t) \exp \left(\beta_{1} x_{1 i}+\ldots+\beta_{k} x_{k i}\right)$, where $h_{i}$ is the hazard rate for the last filing of patent family $i$ to be filed at time $t, h_{0}$ is the baseline hazard, $\mathbf{x}$ is a vector of explanatory variables and $\beta^{\prime}$ s are parameters to be estimated. Hazard ratio estimates smaller than one indicate that a oneunit change in the variable (status change from 0 to 1 for binary variables) is associated with a smaller hazard of the event (filing of the last patent application within the patent family) occurring at time $t$, when other characteristics are held constant. Vice versa, hazard ratio estimates larger than one indicate greater probability of the event occurring.

25 The Cox PH model is a standard method used to analyze survival data and, as a semiparametric model, it requires less than complete distributional specification and makes no assumptions about the baseline hazard's shape (Cox 1972; Cameron \& Trivedi 2005). 
Table 6 Patent family quality

\begin{tabular}{|c|c|c|c|c|c|c|c|c|c|c|}
\hline \multirow{2}{*}{$\begin{array}{l}\text { Dependent variable } \\
\text { Model } \\
\text { Estimate } \\
\text { Sample }\end{array}$} & \multicolumn{2}{|c|}{$\begin{array}{c}\operatorname{Pr}(\text { Grant }=1) \\
\text { Probit } \\
\text { M.E. }\end{array}$} & \multicolumn{2}{|c|}{$\begin{array}{c}\operatorname{Pr}(\text { Cited }=1) \\
\text { Probit } \\
\text { M.E. }\end{array}$} & \multicolumn{2}{|c|}{$\begin{array}{l}\text { Number of citations } \\
\text { Neg. bin. } \\
\text { Coeff. }\end{array}$} & \multicolumn{2}{|c|}{$\begin{array}{l}\text { Patent family size } \\
\text { Zero-inf. neg. bin. } \\
\text { Coeff. }\end{array}$} & \multicolumn{2}{|c|}{$\begin{array}{c}\text { Timespan } \\
\text { Cox PH } \\
\text { Hazard Ratio }\end{array}$} \\
\hline & $\begin{array}{l}\text { Germany } \\
\text { excluded } \\
(1) \\
\end{array}$ & Germany & $\begin{array}{c}\text { Germany } \\
\text { excluded } \\
(3) \\
\end{array}$ & Germany & $\begin{array}{l}\text { Germany } \\
\text { excluded } \\
(5) \\
\end{array}$ & Germany & $\begin{array}{c}\text { Germany } \\
\text { excluded } \\
(7) \\
\end{array}$ & Germany & $\begin{array}{c}\text { Germany } \\
\text { excluded } \\
(9) \\
\end{array}$ & Germany \\
\hline D(UM Priority) & $\begin{array}{c}-0.065^{* * *} \\
(0.008)\end{array}$ & $\begin{array}{c}-0.020 * * * \\
(0.005)\end{array}$ & $\begin{array}{c}-0.059 * * * \\
(0.007)\end{array}$ & $\begin{array}{c}-0.024^{* * *} \\
(0.003)\end{array}$ & $\begin{array}{c}-0.322^{* * *} \\
(0.026)\end{array}$ & $\begin{array}{c}-0.165^{* * *} \\
(0.013)\end{array}$ & $\begin{array}{c}-0.099 * * * \\
(0.011)\end{array}$ & $\begin{array}{c}-0.028^{* * *} \\
(0.006)\end{array}$ & $\begin{array}{c}1.153^{* * *} \\
(0.020)\end{array}$ & $\begin{array}{c}1.111^{* * *} \\
(0.010)\end{array}$ \\
\hline D(Individual applicant) & $\begin{array}{c}-0.139 * * * \\
(0.007)\end{array}$ & $\begin{array}{c}-0.103^{* * *} \\
(0.006)\end{array}$ & $\begin{array}{c}-0.050^{* * *} \\
(0.006)\end{array}$ & $\begin{array}{c}-0.051^{* * *} \\
(0.004)\end{array}$ & $\begin{array}{c}-0.296^{* * *} \\
(0.020)\end{array}$ & $\begin{array}{c}-0.274^{* * *} \\
(0.017)\end{array}$ & $\begin{array}{c}-0.205^{* * *} \\
(0.009)\end{array}$ & $\begin{array}{c}-0.146^{* * *} \\
(0.007)\end{array}$ & $\begin{array}{c}1.088^{* * *} \\
(0.015)\end{array}$ & $\begin{array}{c}-0.951^{* * *} \\
(0.010)\end{array}$ \\
\hline Number of inventors & $\begin{array}{c}0.007^{* * *} \\
(0.002)\end{array}$ & $\begin{array}{l}-0.001 \\
(0.001)\end{array}$ & $\begin{array}{c}0.016^{* * *} \\
(0.002)\end{array}$ & $\begin{array}{c}0.012^{* * *} \\
(0.001)\end{array}$ & $\begin{array}{c}0.081^{* * *} \\
(0.006)\end{array}$ & $\begin{array}{c}0.074^{* * *} \\
(0.002)\end{array}$ & $\begin{array}{c}0.023^{* * *} \\
(0.002)\end{array}$ & $\begin{array}{c}0.018^{* * *} \\
(0.001)\end{array}$ & $\begin{array}{c}0.957^{* * *} \\
(0.004)\end{array}$ & $\begin{array}{c}0.979 * * * \\
(0.002)\end{array}$ \\
\hline D(PCT family) & $\begin{array}{c}0.102^{* * *} \\
(0.005)\end{array}$ & $\begin{array}{c}0.069 * * * \\
(0.003)\end{array}$ & $\begin{array}{c}0.091^{* * *} \\
(0.004)\end{array}$ & $\begin{array}{c}0.080^{* * *} \\
(0.002)\end{array}$ & $\begin{array}{c}0.350 * * * \\
(0.015)\end{array}$ & $\begin{array}{c}0.319 * * * \\
(0.007)\end{array}$ & $\begin{array}{c}0.686^{* * *} \\
(0.007)\end{array}$ & $\begin{array}{c}0.606^{* * *} \\
(0.003)\end{array}$ & $\begin{array}{c}0.557^{* * *} \\
(0.007)\end{array}$ & $\begin{array}{c}0.588^{* * *} \\
(0.004)\end{array}$ \\
\hline Constant & & & & & $\begin{array}{c}1.701^{* * *} \\
(0.103)\end{array}$ & $\begin{array}{c}1.750 * * * \\
(0.043)\end{array}$ & $\begin{array}{c}1.514^{* * *} \\
(0.043)\end{array}$ & $\begin{array}{c}1.298^{* * *} \\
(0.021)\end{array}$ & & \\
\hline $\begin{array}{l}\text { Observations } \\
\text { Log likelihood } \\
\text { Pseudo R2 } \\
\end{array}$ & $\begin{array}{c}39891 \\
-26009.69 \\
0.06 \\
\end{array}$ & $\begin{array}{c}132787 \\
-86767.21 \\
0.04 \\
\end{array}$ & $\begin{array}{c}39891 \\
-20782.16 \\
0.05 \\
\end{array}$ & $\begin{array}{c}132787 \\
-56250.92 \\
0.06 \\
\end{array}$ & $\begin{array}{c}39891 \\
-93870.78\end{array}$ & $\begin{array}{c}132787 \\
-350394.6\end{array}$ & $\begin{array}{c}39891 \\
-92334.91\end{array}$ & $\begin{array}{c}132787 \\
-290072.4\end{array}$ & $\begin{array}{c}39864 \\
-381937.6\end{array}$ & $\begin{array}{c}131457 \\
-1413561\end{array}$ \\
\hline
\end{tabular}

Notes: The sample consists of EPO filings filed 2000-2010, which claim a single patent or single utility model priority filed between $2000-2010$ in Austria, Czech Republic, Denmark, Finland, Germany, Hungary, Italy or Spain. All models include technology field dummies, filing year dummies and priority patent office dummies as controls. Robust standard errors in parentheses. In columns 9 and 10 Cox PH models use Breslow method for ties. ${ }^{* * *},{ }^{* *}$ and ${ }^{*}$ refer to 1\%, 5\% and 10\% significance levels, respectively. Table A.18 (Electronic Supplementary Material) reports the results for the full sample including both Germany and other countries. 
The results in columns 1-8 show a robust negative correlation between the national UM priority indicator and common invention quality measures. It is estimated that EPO filings with a UM priority are approximately 2-7 percentage points less likely to be granted and 2-6 percentage points less likely to receive forward citations. Moreover, EPO filings with UM priorities receive, on average, 0.2-0.3 less forward citations in comparison to EPO filings with patent priorities and have, on average, 0.03-0.1 smaller patent family size. The estimates are consistently smaller for Germany than for other countries. This may indicate that German UM priorities are more often chosen for reasons other than lower invention quality. Thus, Hypothesis 1a, which states that the average quality of EPO filings is lower for UM priority filings, is supported. The finding is consistent with UMs being the appropriate protection method for minor inventions (Johnson 2002; Beneito 2006; Kim et al. 2012; Hamdan-Livramento and Raffo 2016). ${ }^{26}$

The signs of control variables are as expected and in line with the findings of prior studies: individual applicants file patents for inventions that are, on average, of lower quality (Bessen 2008) and the number of inventors reported in a patent is negatively associated with invention quality and the number of forward citations (Sapsalis et al. 2006; Breitzman and Thomas 2015; Dechezleprêtre et al. 2017). Moreover, patent families containing PCT filings are found to be of higher quality.

Columns 9 and 10 indicate that, for EPO filings with UM priorities, the timespan between priority and the last filings is shorter than for EPO filings with patent priorities. This result corroborates the results of Dechezleprêtre et al. (2017), who found that timespan correlates positively with other patent quality measures. It is estimated that a UM priority is associated with a 11-15\% increase in the expected hazard relative to patent priority, holding other variables constant. Hypothesis $1 \mathrm{~b}$ is supported.

We test Hypothesis 2 on filing lags and Hypothesis 3 on grant lags by following the approach of earlier studies, which have modelled patent pendency durations by estimating Cox PH models (e.g., Johnson and Popp 2003; van Zeebroeck 2008; Régibeau and Rockett 2011; Liegsalz and Wagner 2013). The model is, thus, the same as that in columns 9 and 10 in Table 6, where the dependent variable was timespan, except that, now, hazard rate $h_{i}$ is either 1 ) the hazard rate for EPO filing $i$ to be filed at time $t$ (columns 1 and 2 in Table 7) or 2) the hazard rate for a pending EPO filing $i$ to be granted at time $t$ (columns 7 and 8 in Table 7).

In addition to survival models, we analyze, following the approach of Cao (2015) and Cao et al. (2016), whether there exist differences between patent families with UM and patent priorities in the likelihood of subsequent EPO applications being filed "last minute" (i.e., during the last 10 days of the priority year). In columns 3 and 4, we estimate probit models in which the dependent variable is 1 if the subsequent EPO filing is filed within the last 10 days of the priority year and 0 otherwise. We also explore the other filing time extreme by testing whether UM priorities are more likely associated with a subsequent EPO filing within the first 10 days after priority filing. In columns 5 and 6, we estimate probit models in which the dependent variable is 1 if the subsequent EPO filing is filed within the first 10 days of the priority year.

${ }^{26}$ A more comprehensive analysis would also look at the reasons for non-grant (i.e., whether the application is withdrawn or refused; cf. van Zeebroeck, 2008). Moreover, patent quality could also be measured with renewal fee payments. 
Table 7 Filing behavior and grant lags

\begin{tabular}{|c|c|c|c|c|c|c|c|c|}
\hline Dependent variable & \multicolumn{2}{|c|}{ Filing lag } & \multicolumn{2}{|c|}{$\operatorname{Pr}($ Lastminute filing $=1)$} & \multicolumn{2}{|c|}{$\begin{array}{l}\operatorname{Pr}(\text { Filing within first } 10 \\
\text { days }=1)\end{array}$} & \multicolumn{2}{|c|}{ Grant lag } \\
\hline Model & \multicolumn{2}{|c|}{ Cox PH } & \multicolumn{2}{|c|}{ Probit } & \multicolumn{2}{|c|}{ Probit } & \multicolumn{2}{|c|}{ Cox PH } \\
\hline Estimate & \multicolumn{2}{|c|}{ Hazard Ratio } & \multicolumn{2}{|c|}{ M.E. } & \multicolumn{2}{|c|}{ M.E. } & \multicolumn{2}{|c|}{ Hazard Ratio } \\
\hline \multirow[t]{2}{*}{ Sample } & $\begin{array}{l}\text { Germany } \\
\text { excluded }\end{array}$ & Germany & $\begin{array}{l}\text { Germany } \\
\text { excluded }\end{array}$ & Germany & $\begin{array}{l}\text { Germany } \\
\text { excluded }\end{array}$ & Germany & $\begin{array}{l}\text { Germany } \\
\text { excluded }\end{array}$ & Germany \\
\hline & $(1)$ & $(2)$ & (3) & (4) & (5) & (6) & $(7)$ & $(8)$ \\
\hline \multirow[t]{2}{*}{ D(UM Priority) } & $1.078^{* * *}$ & $0.920 * * *$ & $-0.048^{* * *}$ & $0.019 * * *$ & $-0.0014^{*}$ & -0.00002 & 1.010 & $1.055^{* * *}$ \\
\hline & $(0.018)$ & $(0.009)$ & $(0.007)$ & $(0.005)$ & $(0.0009)$ & $(0.001)$ & $(0.030)$ & $(0.015)$ \\
\hline \multirow[t]{2}{*}{ D(Individual applicant) } & $0.908^{* * *}$ & $0.667^{* * *}$ & $0.042^{* * *}$ & $0.186^{* * *}$ & $0.001^{*}$ & $0.015^{* * *}$ & $1.062^{* * *}$ & $1.096^{* * *}$ \\
\hline & $(0.011)$ & $(0.006)$ & $(0.006)$ & $(0.006)$ & $(0.0006)$ & $(0.001)$ & $(0.024)$ & $(0.019)$ \\
\hline \multirow[t]{2}{*}{ Number of inventors } & $0.969^{* * *}$ & $1.017^{* * *}$ & $0.017^{* * *}$ & $-0.008^{* * *}$ & $-0.001^{* * *}$ & $0.002^{* * *}$ & $0.985^{* * *}$ & $0.983^{* * *}$ \\
\hline & $(0.003)$ & $(0.002)$ & $(0.002)$ & $(0.001)$ & $(0.0003)$ & $(0.0002)$ & $(0.006)$ & $(0.002)$ \\
\hline \multirow[t]{2}{*}{ PCT family } & $0.839 * * *$ & $0.798^{* * *}$ & $0.058^{* * *}$ & $0.101^{* * *}$ & 0.0004 & $0.011^{* * *}$ & $0.760 * * *$ & $0.841^{* * *}$ \\
\hline & $(0.008)$ & $(0.004)$ & $(0.005)$ & $(0.003)$ & $(0.0005)$ & $(0.0008)$ & $(0.012)$ & $(0.007)$ \\
\hline Observations & 39826 & 130582 & 39834 & 132489 & 35012 & 132489 & 18385 & 72068 \\
\hline Log likelihood & -387480.29 & -1416618.20 & -23569.07 & -88587.52 & -465.80 & -10769.30 & -161298.14 & -732241.14 \\
\hline Pseudo R2 & & & 0.04 & 0.03 & 0.10 & 0.08 & & \\
\hline
\end{tabular}

Notes: The sample consists of European patents filed 2000-2010, which claim a single patent or single utility model priority filed between 2000-2010 in Austria, Czech Republic, Denmark, Finland, Germany, Hungary, Italy or Spain. Last minute filing indicates that the EPO filing is filed within 10 last days of the priority year. All models include technology field dummies, filing year dummies and priority patent office dummies as controls. Robust standard errors in parentheses. ${ }^{* * *},{ }^{* *}$ and * refer to 1\%,5\% and 10\% significance levels respectively. Table A.19 (Electronic Supplementary Material) reports the results for the sample including both Germany and other countries. 
The models 1-4 concerning filing lags show that the patterns between Germany and other countries differ and have opposite signs. The estimated larger-than-one hazard ratio of the UM priority indicator in column 1 means that EPO filings with UM priorities have, on average, shorter filings lags in other countries. Also, column 3 suggests that EPO filings with UM priorities are 5 percentage points less likely to be filed "last minute" in comparison to patent priorities. These findings are in line with Hypothesis 2. On the contrary, the smaller-than-one hazard ratio in the case of Germany indicates longer filings lags for EPO filings with UM priorities, contradicting Hypothesis 2. Moreover, column 4 shows that EPO filings with German UM priorities are approximately 2 percentage points more likely to be filed "last minute". Columns 5 and 6 do not show significant differences between UM and patent priorities with respect to very short filing lags. This might be due to the very small number of fast filings as demonstrated in Figure 5 and Figure A.3 in the online appendix (Electronic Supplementary Material). We may conclude that there exists country-specific heterogeneity in filing lag patterns, and Hypothesis 2 is supported only by the "other countries" sample.

Model 8 shows that German UM priorities have a statistically significantly higher hazard rate than German patent priorities, indicating that EPO filings with German UM priorities have shorter grant lags. It is estimated that EPO filings with German UM priorities are associated with approximately $6 \%$ higher expected hazard in comparison to EPO filings with German patent priorities, holding other variables constant. Model 7 shows that there is no similar significant difference for the "other countries" sample. Hypothesis 3 is thus supported, but only for the German sample.

Interestingly, PCT filings are associated with longer filing (models 1-2) and grant lags (columns 7-8) and higher likelihood of "last minute" filings (models 3-4). This is consistent with the reasoning that PCT filings are used when the applicant is not sure about the commercial potential of the invention and "buys time" to further evaluate it by choosing the PCT route (Guellec and van Pottelsberghe 2002; Radauer et al. 2015).

To summarize, we find robust support for Hypotheses 1a and 1b: UM priorities are systematically associated with lower quality of inventions in EPO filings. The findings regarding Hypotheses 2 and 3 are less consistent and indicate country-level heterogeneity in filing and grant lag differences.

\subsection{Robustness checks}

We tested the robustness of the results using restricted samples and alternative model specifications. All robustness check estimations are reported in the online appendix (Tables A.15-A.17 in Electronic Supplementary Material).

\subsubsection{Quality}

First, the average quality of inventions for which EPO patents have been granted is likely quite different from the average quality of inventions for which EPO patent applications were made but no EPO patent was granted. Since the sample in our main analysis contains both granted and non-granted European patent filings, it means that all filings have not been subject to a similar examination process at the EPO. Moreover, non-granted EPO filings include those that were withdrawn by applicants during the examination process. It 
should be noted that such withdrawals comprise most "not granted" EPO applications. Lazaridis and van Pottelsberghe (2007) report that 30-35\% of EPO patent applications are withdrawn by applicants during the examination process while only approximately $5 \%$ are rejected by examiners. The rest $(60 \%)$ are granted. The pendency lags of European patents from filing to grant are approximately four years (Harhoff and Wagner 2009). Thus, we estimate all the models in Table 6 by using a subsample of granted EPO filings with patent or UM priorities.

Table A.15 in the online appendix (Electronic Supplementary Material) reports the results. The observed patterns are similar to those in Table 6. Again, we find a robust negative association between the UM priority indicator and the quality of EPO filing for both granted and non-granted subsamples. Hypothesis $1 \mathrm{a}$ and $1 \mathrm{~b}$ get further support. Unlike in Table 6, here, we do not observe a difference in the average patent family size between granted EPO patent families with patent and UM priorities for the Germany sample (Table A.15 (B), model 5). Thus, it seems that the quality difference between EPO filings with German UM and German patent priorities is higher for non-granted EPO applications than for granted EPO patents.

Second, in most countries, UMs cannot be used to protect process inventions. Thus, some share of EPO filings with patent priorities is presumably filed to protect process inventions whereas UMs are primarily used to protect product inventions. To partly account for this, we try to identify EPO filings with process inventions. This is done by searching the titles of EPO filings and excluding from the sample filings with the words "process", "method", "procedure", "technique" or "system" in their titles. Table A.16 (Electronic Supplementary Material) reports the results for this restricted sample and demonstrates that the results of Table 6 are robust. Hypotheses $1 \mathrm{a}$ and $1 \mathrm{~b}$ get further support.

\subsubsection{Filing and grant lags}

The Cox PH model is only one alternative among several models that are suitable for the analysis of survival data (see Kalbfleisch and Prentice 2002). Alternatively, we estimate accelerated failure time models and ordinary least squares (OLS) models (cf. Harhoff and Wagner 2009; Berger et al. 2012). The results are reported in Table A.17 in the online appendix (Electronic Supplementary Material). In columns 1, 2, 5 and 6, the dependent variable is the logarithm of filing lag and grant lag. In columns 3, 4, 7 and 8, the accelerated failure time model assumes log-logistic distribution of survival time following prior studies (Wagner and Harhoff 2009; Berger et al. 2012).

The signs of estimates in Table A.17 indicate that UM priorities are associated with shorter filings lags in both Germany and other countries and with shorter grant lags in Germany. The estimates are statistically significant at $1 \%$ a significance level. For other countries, no difference is found in grant lags between EPO filings with patent and UM priorities which is consistent with Table 7. Thus, the robustness checks partly corroborate the findings in the main analysis but partly contradict them. On one hand, further evidence is found in support of Hypothesis 2 for the sample consisting of other countries. On the other hand, in the case of Germany, Table 7 and Table A.16 display opposite results concerning the filing lag difference between UM and patent priorities. In case of grant lags, the results in these two tables tell a similar story. 
When the Cox PH model is used and time is assumed to be continuous, the tied survival times in the data must be treated one way or another in estimations. The models in Tables 6 and 7 used the Breslow method for ties. It is computationally the least demanding and is the default option in several statistical packages, but leads to inconsistent estimates when there are many ties in the data (Kalbfleisch and Prentice 2002). In our data set there are many ties since several patent families have equal filing lags and timespans and several EPO filings have equal grant lags. We use the method suggested by Borucka (2014) to test whether the ties affect the estimates: We subtract from our duration variables (filing and grant lags and timespan) random numbers from a uniform distribution [0, 0.001]. Doing this, we artificially reduce the number of ties to close to zero. The estimations with this amended data produce similar results. These alternative estimations are not reported here but are available from the authors upon request.

\section{Concluding remarks}

This research highlights that UMs (and other equivalent second-tier patents) should be taken into account when patent family structures are analyzed. Our empirical analysis provides suggestive evidence that priority UM filings are associated with lower quality in EPO filings in comparison to EPO filings with patent priorities. Hence, UM priorities may signal lower quality of the underlying invention and may complement existing indicators of patent value, such as patent family size. However, analyses of filing and grant lags provide more mixed evidence and paint a more nuanced portrait of the UM. EPO filings with UM members tend to have shorter filing and grant lags, suggesting that besides value of invention, time considerations too, drive the choice to file UMs. In this respect we also observe heterogeneity across countries.

This study sheds light on the role of UMs in patent filing strategies. We introduced a simple typology of patent families with UM members. When the classification is applied to patent families with European UM members, it is documented that 1) most UMs are filed to protect inventions nationally; 2) the use of UMs as part of international patent filing strategies is heterogeneous across Europe (in certain patent offices, it is frequent, whereas in others, its prevalence is negligible); and 3) UMs are used as priorities for subsequent transnational patents (EPO and PCT patent families). The third observation implies that UMs are not only a proxy for incremental inventions but that they also widen the set of international patent filing strategies available to applicants.

There exist plentiful avenues for future research, which we could not address in the current study. Differences in the role of UMs in patent strategies across technology classes and industries remain an important research topic as presumably UMs affect competition and innovation activity differently across sectors. Moreover, the motives to use UMs also differ across countries and industries. Since national IPR systems have their institutional peculiarities, country-specific case studies would be informative about the functioning of heterogeneous UM systems. An important enabler of future research of UM systems would be construction of an international panel dataset that tracks the evolution of national IPR institutions, including how dimensions of national patent and UM systems (renewal fees, term of protection, inventive step requirement, novelty requirement, stringency of examination) have changed over time. Regarding specific motives to use 
UMs, future studies could analyze how large a share of UM filings aim to pre-empt competitors from patenting and how the utilization of UMs as part of international patenting strategies has evolved over time. In particular, how UMs are utilized as part of international PCT filings is an important topic for future research. Finally, the future propensity-to-patent analyses should explicitly mention whether UM filings are taken into account in calculating the patenting propensities. Comparisons of patenting propensities between firms, industries and countries will otherwise remain incomplete.

\section{Acknowledgements}

We thank Ari Hyytinen, Mika Maliranta, Heli Koski, Aija Leiponen and two anonymous reviewers for comments. Earlier versions of this paper have been presented in the student seminar of Jyväskylä University School of Business and Economics, in a seminar at Tilburg University and in the JSBE Breakfast Seminar. Financial support from OP Group Research Foundation and Yrjö Jahnsson foundation is gratefully acknowledged. 


\section{References}

Beneito, P. 2006. The innovative performance of in-house and contracted R\&D in terms of patents and utility models. Research Policy 35, 502-517.

Berger, F., Blind, K. \& Thumm, N. 2012. Filing behaviour regarding essential patents in industry standards. Research Policy 41, 216-225.

Bessen, J. 2008. The value of U.S. patents by owner and patent characteristics. Research Policy 37, 932-945.

Björkwall, P. 2009. Nyttighetsmodeller : Ett ändamålsenligt innovationsskydd? Doctoral dissertation. Svenska handelshögskolan, Helsinki.

Blind, K., Edler, J., Frietsch, R. \& Schmoch, U. 2006. Motives to patent: evidence from Germany. Research Policy 35, 655-672.

Borucka, J. 2014. Methods for handling tied events in the Cox proportional hazard model. Studia Oeconomica Posnaniensia 2(2), 91-106.

Breitzman, A. \& Thomas, P. 2015. Inventor team size as a predictor of the future citation impact of patents. Scientometrics 103, 631-647.

Burke, P. \& Reitzig, M. 2007. Measuring patent assessment quality - Analyzing the degree and kind of (in)consistency in patent offices' decision making. Research Policy 36, 1404-1430.

Cameron, C. \& Trivedi, P. 2005. Microeconometrics: Methods and applications. Cambridge University Press.

Cao, S. 2015. Patent system, firm patenting strategy and technology progress. PhD thesis, University of California, Berkeley.

Cao, S., Lei, Z. \& Wright, B. 2016. Speed of Patent Protection, Rate of Technical Knowledge Obsolescence and Optimal Patent Strategy: Evidence from Innovations Patented in the US, China and several other countries. A paper presented at IP Statistics for Decision Makers 2016 conference in Sydney. Available at: https://www.ipsdm2016.com/wp-content/uploads/2016/12/Cao-Lei-andWright.pdf

Cox, D. 1972. Regression models and life-tables. Journal of the Royal Statistical Society Series B 34(2), 187-220.

Cremers, K., Ernicke, M., Gaessler, F., Harhoff, D., Helmers, C., McDonagh, L., Schliessler, P., van Zeebroeck, N. 2017. Patent litigation in Europe. European Journal of Law and Economics 44, 1-44.

Dechezleprêtre, A., Ménière, Y. \& Mohnen, M. 2017. International patent families: from application strategies to statistical indicators. Scientometrics 111, 793-828.

de Rassenfosse, G., Dernis, H., Guellec, D., Picci. L. \& van Pottelsberghe de la Potterie, B. 2013. The worldwide count of priority patents: A new indicator of inventive activity. Research Policy 42, 720-737.

de Rassenfosse, G., Jaffe, A. \& Webster, E. 2016. Low-quality patents in the eye of the beholder: evidence from multiple examiners. National Bureau of Economic Research working paper No. 22244.

de Rassenfosse, G. \& van Pottelsberghe de la Potterie, B. 2013. The role of fees in patent systems: Theory and evidence. Journal of Economic Surveys 27(4), 696-716.

de Saint-Georges, M. \& van Pottelsberghe de la Potterie, B. 2013. A quality index for patent systems. Research Policy 42, 704-719. 
Dernis, H., \& Khan, M. 2004. Triadic patent families methodology. OECD STI Working Paper 2004/2.

European Commission. 1995. Green Paper: The Protection of Utility Models in the Single Market. Green Paper COM(95), 370 final. Brussels, 19.07.1995.

European Commission. 2002. SEC(2001)1307. Summary report of replies to the questionnaire on the impact of the Community utility model with a view to updating the Green Paper on protection by the utility model in the internal market.

European Patent Office. 2016. PATSTAT Data Catalog Version 5.06, 2016 Spring Edition.

Frietsch, R., Neuhäusler, P. \& Rothengatter, O. 2013. Which road to take? Filing routes to the European Patent Office. World Patent Information 35, 8-19.

Frietsch, R. \& Schmoch, U. 2010. Transnational patents and international markets. Scientometrics 82, 185-200.

Frietsch, R., Schmoch, U., van Looy, J., Walsh, P., Devroede, R., Du Plessis, M., Jung, T., Meng, Y., Neuhäusler, P., Peeters, B. \& Schubert, T. 2010. The value and indicator function of patents. Fraunhofer Institute for Systems and Innovation Research.

Gilbert, R. \& Newbery, D. 1982. Preemptive patenting and the persistence of monopoly. The American Economic Review 72(3), 514-526.

Guellec, D. \& van Pottelsberghe de la Potterie, B. 2000. Applications, grants and the value of patent. Economics Letters 69, 109-114.

Guellec, D. \& van Pottelsberghe de la Potterie, B. 2002. The value of patents and patenting strategies - countries and technology areas patterns. Economics of Innovation and New Technology 11(2), 133-148.

Guellec, D. \& van Pottelsberghe de la Potterie, B. 2007. The economics of the European patent system. Oxford University Press.

Guellec, D., Martínez, C. \& Zuniga, P. 2012. Pre-emptive patenting: securing market exclusion and freedom of operation. Economics of Innovation and New Technology 21(1), 1-29.

Hall, B., Helmers, C., Rogers, M. \& Sena, V. 2014. The choice between formal and informal intellectual property: A review. Journal of Economic Literature 52(2), 375-423.

Hamdan-Livramento, I. \& Raffo, J. 2016. What is an incremental but non-patentable invention? WIPO, Economics and Statistics Division working paper. Available at: https://www.oecd.org/sti/157\%20\%20OECD\%20Hamdan\%20Raffo\%202016\%205092016.pdf

Harhoff, D., Scherer, F. \& Vopel, K. 2003. Citations, family size, opposition and the value of patent rights. Research Policy 32(8), 1343-1363.

Harhoff, D. \& Wagner, S. 2009. The duration of patent examination at the European Patent Office. Management Science 55(12), 1969-1984.

Heikkilä, J. 2017. The relationship between patent and second tier patent protection: The abolition of the Dutch short-term patent system. Available at http://dx.doi.org/10.2139/ssrn.2958107

Heikkilä, J. \& Lorenz, A. 2018. Need for speed? Exploring the relative importance of patents and utility models among German firms. Economics of Innovation and New Technology 27(1), 80-105.

Heikkilä, J. \& Verba, M. 2017. Do two-tiered patent systems induce sorting? Evidence from European countries. Mimeo. 
Henkel, J. \& Lernbecher (neé Pangerl), S. 2008. Defensive Publishing - An Empirical Study. Available at https:// ssrn.com/abstract $=981444$

Janis, M. 1999. Second tier patent protection. Harvard International Law Journal 40(1), 151219.

Johnson, D. 2002. “Learning-by-Licensing": R\&D and Technology Licensing in Brazilian Invention. Economics of Innovation and New Technology 11(3), 163-177.

Johnson, D. \& Popp, D. 2003. Forced out of the closet: The impact of the American Inventors Protection Act on the timing of patent disclosure. The RAND Journal of Economics 34(1), 96-112.

Kalbfleisch, J. \& Prentice, R. 2002. Statistical analysis of failure time data. Second edition. Wiley series in probability and statistics, John Wiley \& Sons.

Kim, Y., Lee, K., Park, W. \& Choo, K. 2012. Appropriate intellectual property protection and economic growth in countries at different levels of development. Research Policy 41(2), 358-375.

Lanjouw, J., Pakes, A. \& Putnam, J. 1998. How to count patents and value intellectual property: The uses of patent renewal and application data. The Journal of Industrial Economics 46(4), 405-432.

Lanjouw, J. \& Schankerman, M. 2004. Patent quality and research productivity: Measuring innovations with multiple indicators. The Economic Journal 114, 441-465.

Lazaridis, G. \& van Pottelsberghe de la Potterie. 2007. The rigour of EPO's patentability criteria: An insight into the "induced withdrawals". World Patent Information 29, 317-326.

Liegsalz, J. \& Wagner, S. 2013. Patent examination at the State Intellectual Property Office in China. Research Policy 42, 552-563.

Martínez, C. 2011. Patent families: When do different definitions really matter? Scientometrics 86, 39-63.

Palangkaraya, A., Jensen, P. \& Webster, E. 2008. Applicant behavior in patent examination request lags. Economic Letters 101, 243-245.

Picard, P. \& van Pottelsberghe de la Potterie. 2013. Patent office governance and patent examination quality. Journal of Public Economics 104, 14-25.

Prud'homme, D. 2014. Creating a "model" utility model system: A comparative analysis of the utility model systems in Europe and China. IP Key Project Working Paper Series. Available at: http:/ / papers.ssrn.com/sol3/papers.cfm?abstract_id=2541900

Putnam, J. 1996. The value of international patent rights. Ph.D. Thesis. Yale University, Yale.

Radauer, A., Rosemberg, C., Cassagneau-Francis, O., Goddar, H. \& Haarmann, C. 2015. Study on the economic impact of the utility model legislation in selected Member States: Final Report. A study tendered by the European Commission - DG Internal Market and Services in 2013, MARKT/2013/065/D2/ST/OP.

Régibeau, P. \& Rockett, K. 2010. Innovation cycles and learning at the patent office: Does early patent get delay? The Journal if Industrial Economics 63(2), 222-246.

Reitzig, M. 2004. Improving patent valuations for management purposes - validating new indicators by analyzing application rationales. Research Policy 33, 939-957.

Sapsalis, E., van Pottelsberghe de la Potterie, B. \& Navon, R. 2006. Academic versus industry patenting: An in-depth analysis of what determines patent value. Research Policy 35, 1631-1645. 
Squicciarini, M., Dernis, H. \& Criscuolo, C. 2013. Measuring Patent Quality: Indicators of Technological and Economic Value. OECD Science, Technology and Industry Working Paper 2013/03.

Sternitzke, C. 2009a. The international preliminary examination of patent applications filed under the Patent Cooperation Treaty - a proxy for patent value? Scientometrics 78(2), 189-202.

Sternitzke, C. 2009b. Defining triadic patent families as a measure of technological strength. Scientometrics 81(1), 91-109.

Stevnsborg, N. \& van Pottelsberghe de la Potterie. 2007. Patenting procedures and filing strategies at the EPO. In The economics of the European patent system, ed. D. Guellec and B. van Pottelsberghe de la Potterie, chapter 6, 155-83. Oxford: Oxford University Press.

Suthersanen, U. 2006. Utility models and innovation in developing countries. The International Centre for Trade and Sustainable Development Issue Paper 13, UNCTAD.

van Pottelsberghe de la Potterie, B. \& van Zeebroeck, N. 2008. A brief history of space and time: The scope-year index as a patent value indicator based on families and renewals. Scientometrics 75(2), 319-338.

van Pottelsberghe de la Potterie, B. 2011. The quality factor in patent systems. Industrial and Corporate Change 20(6), 1755-1793.

van Zeebroeck, N. 2008. Essays on the empirical analysis of patent systems. PhD thesis, Free University of Brussels, Solvay Business School.

van Zeebroeck, N. 2011. The puzzle of patent value indicators. Economics of Innovation and New Technology 20(1), 33-62.

van Zeebroeck, N. \& van Pottelsberghe de la Potterie, B. 2011. Filing strategies and patent value. Economics of Innovation and New Technology 20(6), 539-561.

Webster, E., Palangkaraya, A. \& Jensen, P. 2007. Characteristics of international patent application outcomes. Economic Letters 95, 362-368.

Webster, E., Jensen, P. \& Palangkaraya, A. 2014. Patent examination outcomes and the national treatment principle. RAND Journal of Economics 45(2), 449-469.

WIPO. 2008. WIPO Intellectual Property Handbook: Policy, Law and Use. WIPO Publication No. 489. 


\section{Appendix}
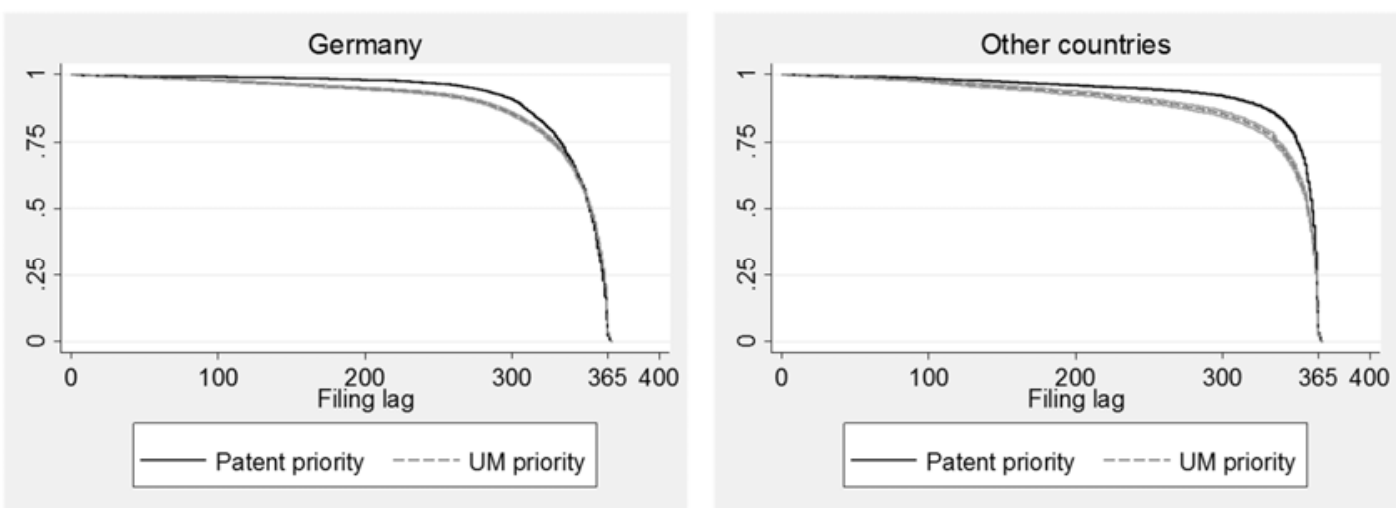

Fig 5. Kaplan-Meier survivor function, filing lags. Filing lag refers to elapsed days from the priority filing date until filing of a subsequent EPO application. EPO patent applications with filing lags longer than 368 days are excluded. Other countries include Austria, the Czech Republic, Denmark, Spain, Finland, Hungary and Italy. 90\% confidence intervals displayed.
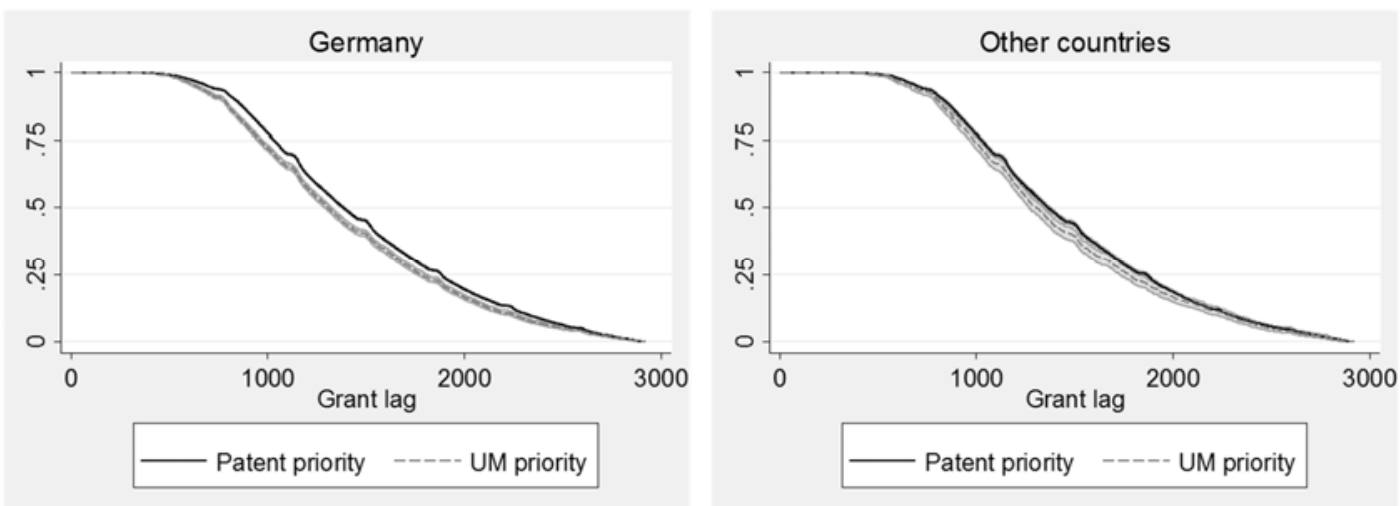

Fig 6. Kaplan-Meier survivor functions, grant lags. Grant lag refers to the number of days elapsed from the filing of an EPO application until its grant. EPO patents with grant lags longer than eight years are excluded. $90 \%$ confidence intervals displayed. 

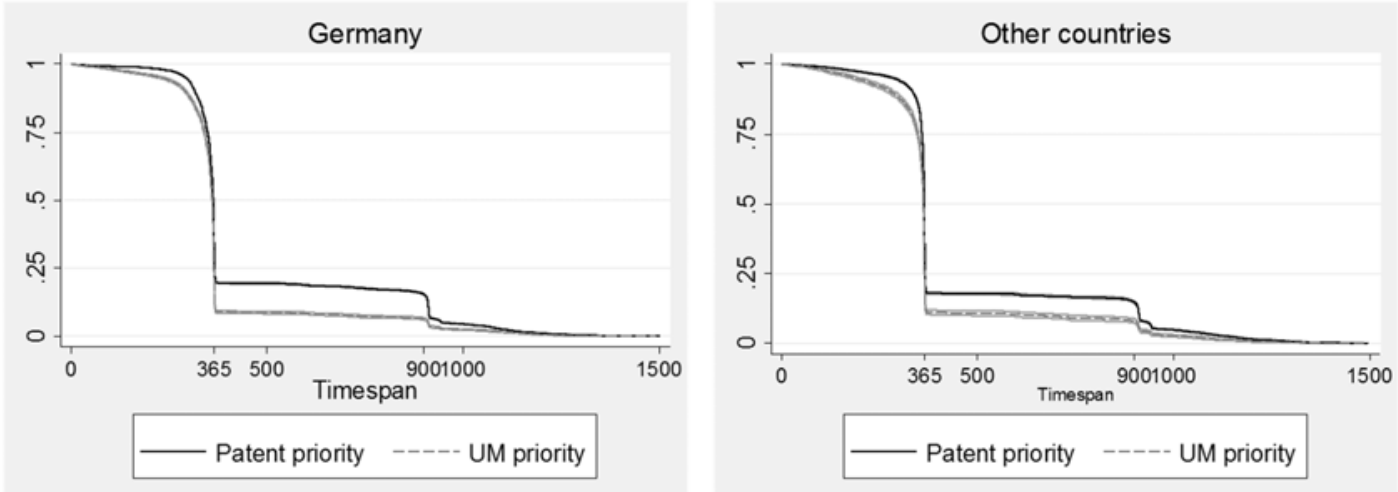

Fig 7. Kaplan-Meier survivor functions, timespans. Timespan is the elapsed days between the priority filing date and the filing date of the last patent filing within the patent family. Patent families with timespans longer than 1500 days are excluded. $90 \%$ confidence intervals displayed. 
Table A.1 International patent family dyads, Austria

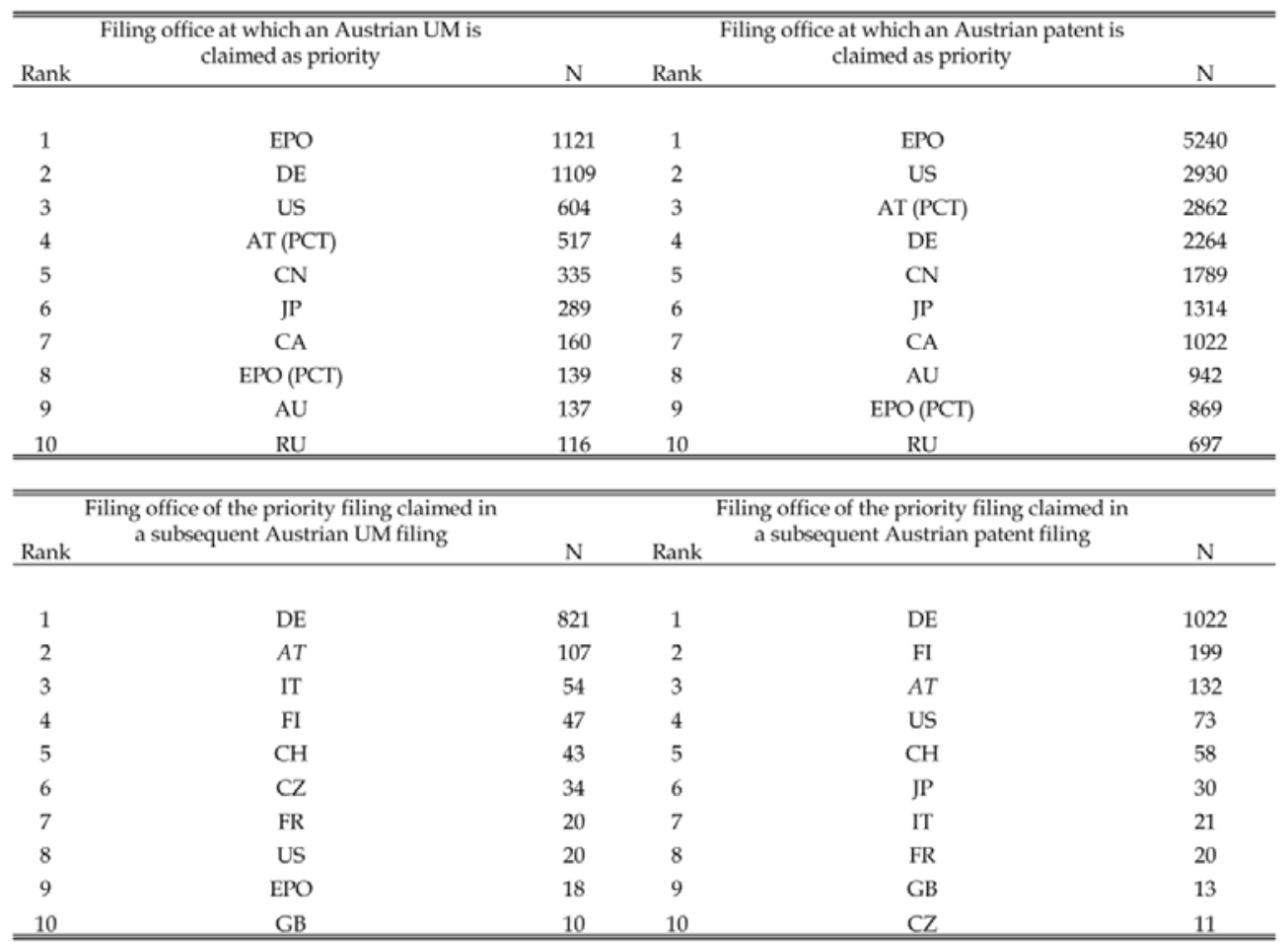

Table A.2 International patent family dyads, Czech Republic

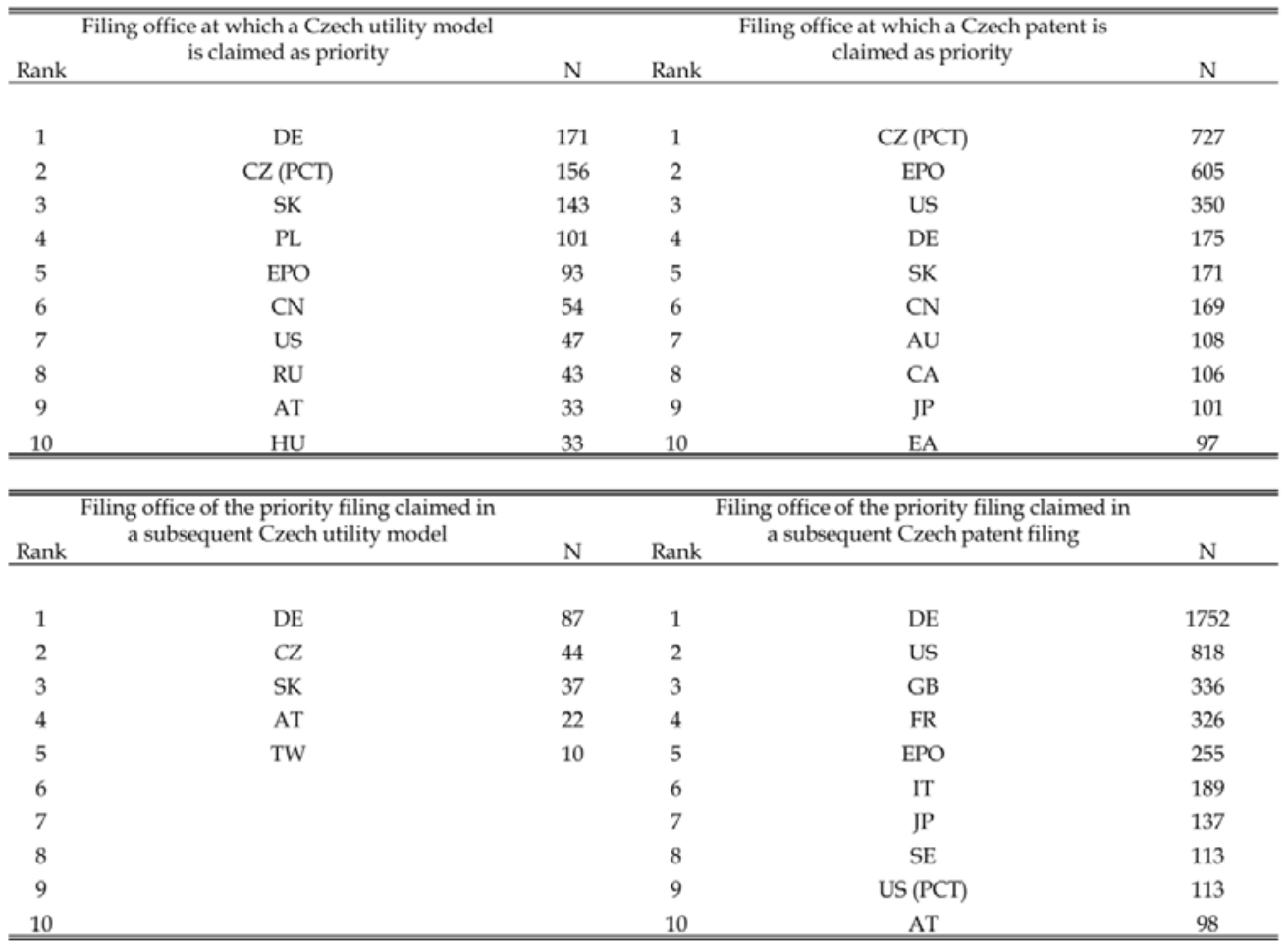


Table A.3 International patent family dyads, Germany

\begin{tabular}{|c|c|c|c|c|c|}
\hline \multirow{2}{*}{\multicolumn{2}{|c|}{$\begin{array}{l}\text { Filing office at which a German UM is } \\
\text { claimed as priority }\end{array}$}} & \multicolumn{4}{|c|}{$\begin{array}{l}\text { Filing office at which a German patent is } \\
\text { claimed as priority }\end{array}$} \\
\hline & & $\mathrm{N}$ & Rank & & $\mathrm{N}$ \\
\hline 1 & EPO & 18540 & 1 & EPO & 163256 \\
\hline 2 & US & 8282 & 2 & US & 129187 \\
\hline 3 & $\mathrm{EPO}(\mathrm{PCT})$ & 6534 & 3 & $\mathrm{EPO}(\mathrm{PCT})$ & 95896 \\
\hline 4 & $\mathrm{CN}$ & 3890 & 4 & JP & 62106 \\
\hline 5 & $\mathrm{JP}$ & 2887 & 5 & $\mathrm{CN}$ & 60661 \\
\hline 6 & $D E$ & 2623 & 6 & $D E$ & 25813 \\
\hline 7 & $\mathrm{DE}(\mathrm{PCT})$ & 1836 & 7 & $\mathrm{DE}(\mathrm{PCT})$ & 24633 \\
\hline 8 & $\mathrm{AU}$ & 1518 & 8 & $\mathrm{KR}$ & 24118 \\
\hline 9 & $\mathrm{CA}$ & 1398 & 9 & $\mathrm{CA}$ & 19714 \\
\hline 10 & RU & 1240 & 10 & $\mathrm{AU}$ & 17586 \\
\hline \multirow{2}{*}{\multicolumn{2}{|c|}{$\begin{array}{l}\text { Filing office of the priority filing claimed in } \\
\text { a subsequent German UM filing } \\
\text { Rank }\end{array}$}} & \multirow{2}{*}{\multicolumn{4}{|c|}{$\begin{array}{l}\text { Filing office of the priority filing claimed in } \\
\text { a subsequent German patent filing }\end{array}$}} \\
\hline & & $\mathrm{N}$ & Rank & & $\mathrm{N}$ \\
\hline 1 & $D E$ & 3022 & 1 & US & 41151 \\
\hline 2 & TW & 2075 & 2 & $\mathrm{JP}$ & 34733 \\
\hline 3 & AT & 1068 & 3 & $D E$ & 24974 \\
\hline 4 & $\mathrm{CN}$ & 728 & 4 & EPO & 11539 \\
\hline 5 & US & 669 & 5 & FR & 10429 \\
\hline 6 & EPO & 578 & 6 & GB & 7384 \\
\hline 7 & IT & 558 & 7 & KR & 6406 \\
\hline 8 & FR & 389 & 8 & IT & 5084 \\
\hline 9 & GB & 301 & 9 & SE & 2987 \\
\hline 10 & $\mathrm{FI}$ & 271 & 10 & AT & 2289 \\
\hline
\end{tabular}

Table A.4 International patent family dyads, Denmark

\begin{tabular}{|c|c|c|c|c|c|}
\hline \multirow{2}{*}{\multicolumn{2}{|c|}{$\begin{array}{l}\text { Filing office at which a Danish utility } \\
\text { model is claimed as priority }\end{array}$}} & \multirow{2}{*}{\multicolumn{4}{|c|}{$\begin{array}{l}\text { Filing office at which a Danish patent is } \\
\text { claimed as priority }\end{array}$}} \\
\hline & & $\mathrm{N}$ & Rank & & $\mathrm{N}$ \\
\hline 1 & EPO & 77 & 1 & EPO & 981 \\
\hline 2 & DK (PCT) & 66 & 2 & DK (PCT) & 929 \\
\hline 3 & US & 30 & 3 & US & 690 \\
\hline 4 & $\mathrm{DE}$ & 28 & 4 & $\mathrm{CN}$ & 381 \\
\hline 5 & $\mathrm{AU}$ & 19 & 5 & $\mathrm{AU}$ & 271 \\
\hline 6 & $D K$ & 17 & 6 & $\mathrm{CA}$ & 245 \\
\hline 7 & NO & 10 & 7 & $\mathrm{DE}$ & 241 \\
\hline 8 & & & 8 & JP & 216 \\
\hline 9 & & & 9 & NO & 134 \\
\hline 10 & & & 10 & KR & 100 \\
\hline \multicolumn{2}{|c|}{$\begin{array}{l}\text { Filing office of the priority filing claimed in } \\
\text { a subsequent Danish utility model filing }\end{array}$} & \multicolumn{4}{|c|}{$\begin{array}{l}\text { Filing office of the priority filing claimed in } \\
\text { a subsequent Danish patent filing }\end{array}$} \\
\hline Rank & & $\mathrm{N}$ & Rank & & $\mathrm{N}$ \\
\hline 1 & $\mathrm{DE}$ & 43 & 1 & US & 161 \\
\hline 2 & FI & 32 & 2 & $\mathrm{DE}$ & 111 \\
\hline 3 & $D K$ & 15 & 3 & NO & 61 \\
\hline 4 & US & 12 & 4 & FR & 28 \\
\hline 5 & & & 5 & FI & 27 \\
\hline 6 & & & 6 & SE & 25 \\
\hline 7 & & & 7 & $D K$ & 16 \\
\hline 8 & & & 8 & GB & 13 \\
\hline 9 & & & 9 & JP & 12 \\
\hline 10 & & & 10 & EPO & 10 \\
\hline
\end{tabular}


Table A.5 International patent family dyads, Estonia

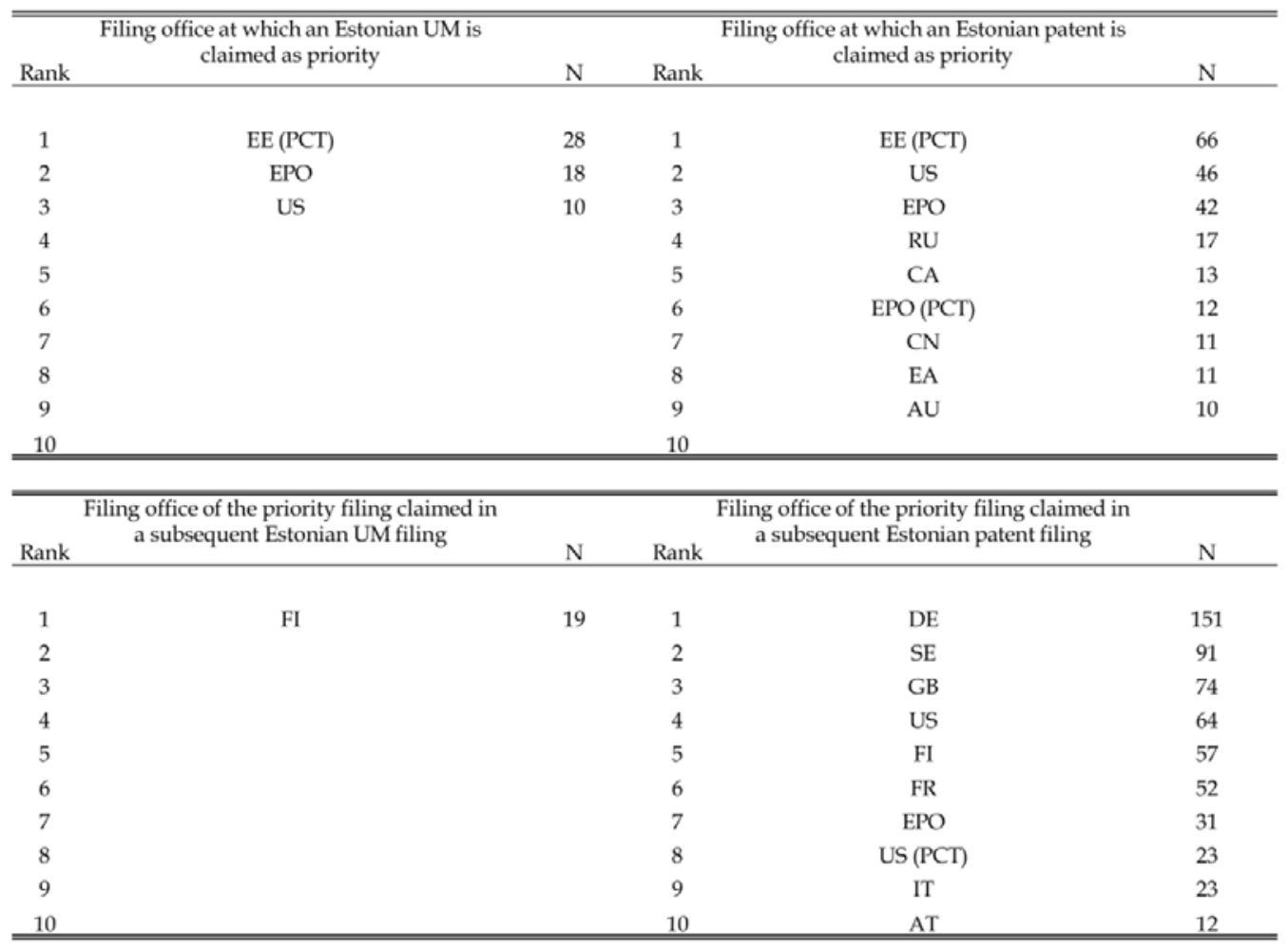

Table A.6 International patent family dyads, Spain

\begin{tabular}{|c|c|c|c|c|c|}
\hline \multirow{2}{*}{\multicolumn{2}{|c|}{$\begin{array}{l}\text { Filing office at which a Spanish UM is } \\
\text { claimed as priority }\end{array}$}} & \multicolumn{4}{|c|}{$\begin{array}{l}\text { Filing office at which a Spanish patent is } \\
\text { claimed as priority }\end{array}$} \\
\hline & & $\mathrm{N}$ & Rank & & $\mathrm{N}$ \\
\hline 1 & EPO & 341 & 1 & EPO & 1447 \\
\hline 2 & $\mathrm{DE}$ & 262 & 2 & US & 960 \\
\hline 3 & FR & 237 & 3 & $\mathrm{DE}$ & 707 \\
\hline 4 & IT & 180 & 4 & $\mathrm{ES}(\mathrm{PCT})$ & 624 \\
\hline 5 & PT & 159 & 5 & $\mathrm{CN}$ & 430 \\
\hline 6 & US & 153 & 6 & $\mathrm{JP}$ & 425 \\
\hline 7 & $\mathrm{ES}$ (PCT) & 106 & 7 & $\mathrm{CA}$ & 360 \\
\hline 8 & $\mathrm{CN}$ & 93 & 8 & $\mathrm{AU}$ & 354 \\
\hline 9 & $\mathrm{BR}$ & 49 & 9 & BR & 312 \\
\hline 10 & $\mathrm{CA}$ & 49 & 10 & $\mathrm{MX}$ & 294 \\
\hline \multirow{2}{*}{\multicolumn{2}{|c|}{$\begin{array}{l}\text { Filing office of the priority filing claimed in } \\
\text { a subsequent Spanish UM filing } \\
\text { Rank } \quad \text {. }\end{array}$}} & \multicolumn{4}{|c|}{$\begin{array}{l}\text { Filing office of the priority filing claimed in } \\
\text { a subsequent Spanish patent filing }\end{array}$} \\
\hline & & $\mathrm{N}$ & Rank & & $\mathrm{N}$ \\
\hline 1 & IT & 236 & 1 & $\mathrm{DE}$ & 334 \\
\hline 2 & $\mathrm{DE}$ & 185 & 2 & FR & 263 \\
\hline 3 & FR & 40 & 3 & $J P$ & 229 \\
\hline 4 & $\mathrm{CN}$ & 39 & 4 & IT & 189 \\
\hline 5 & TW & 30 & 5 & US & 126 \\
\hline 6 & AT & 16 & 6 & KR & 103 \\
\hline 7 & US & 15 & 7 & ES & 75 \\
\hline 8 & PT & 14 & 8 & GB & 30 \\
\hline 9 & TR & 14 & 9 & TW & 30 \\
\hline 10 & GB & 11 & 10 & $\mathrm{FI}$ & 22 \\
\hline
\end{tabular}


Table A.7 International patent family dyads, Finland

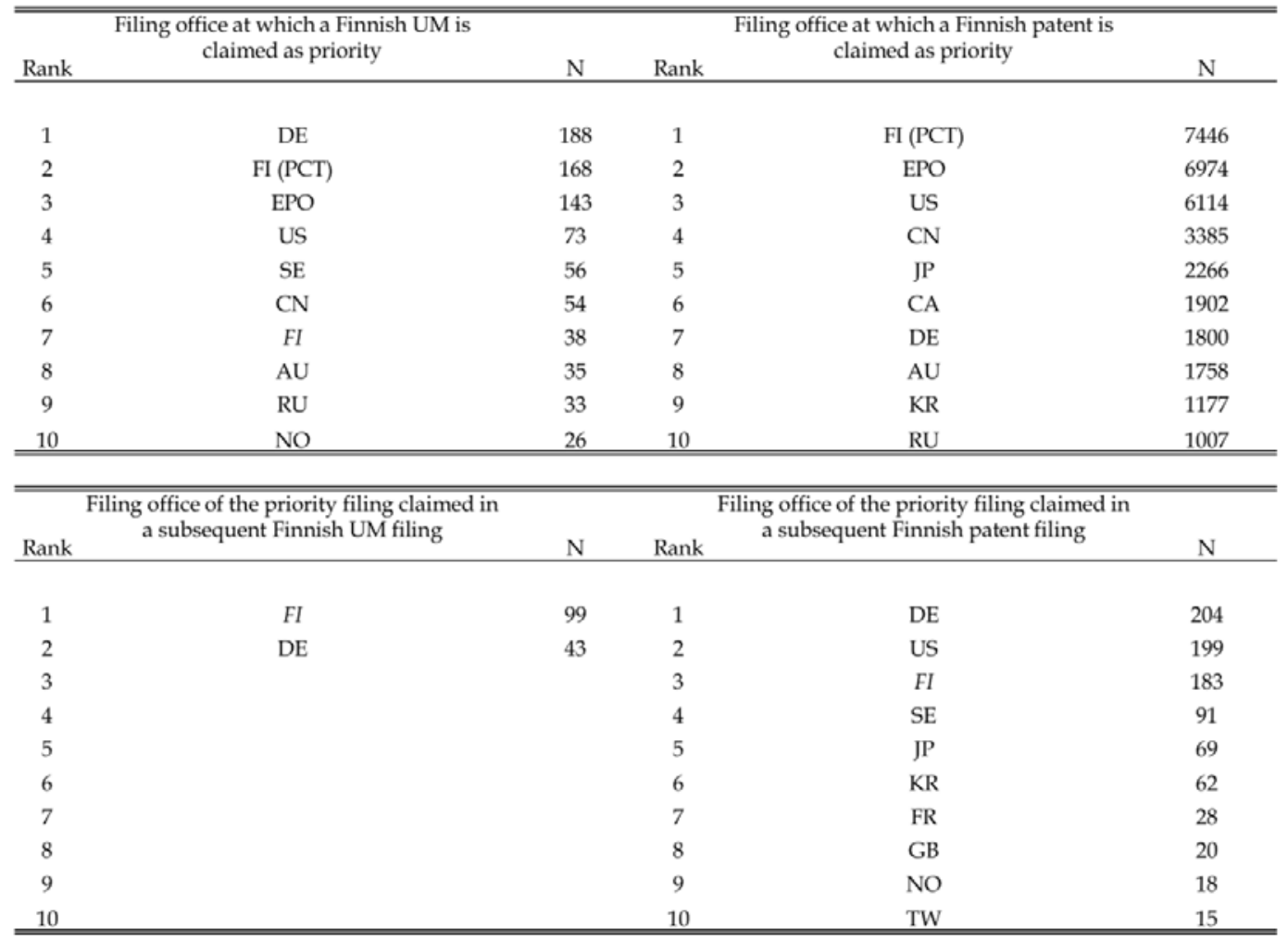

Table A.8 International patent family dyads, France

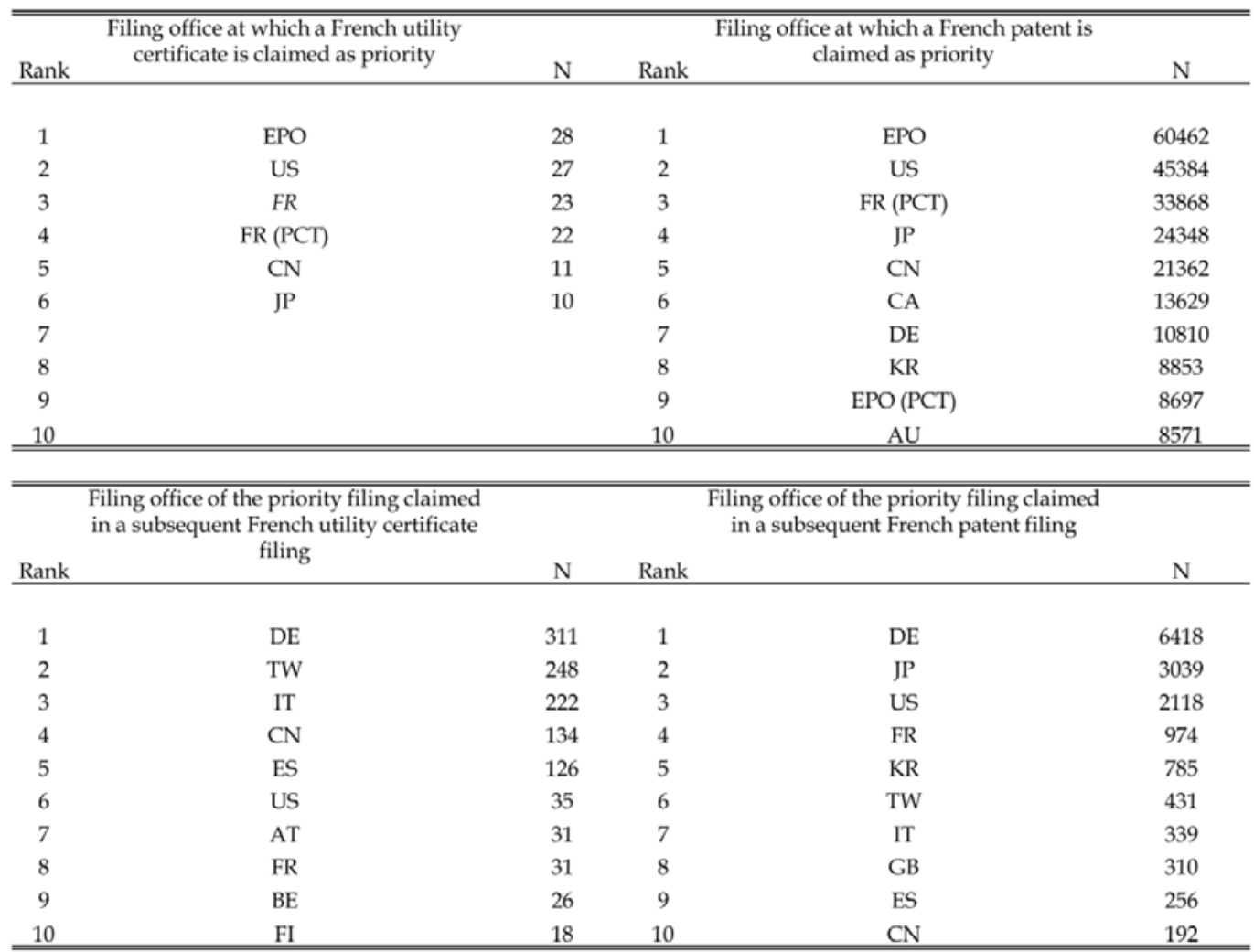


Table A.9 International patent family dyads, Hungary

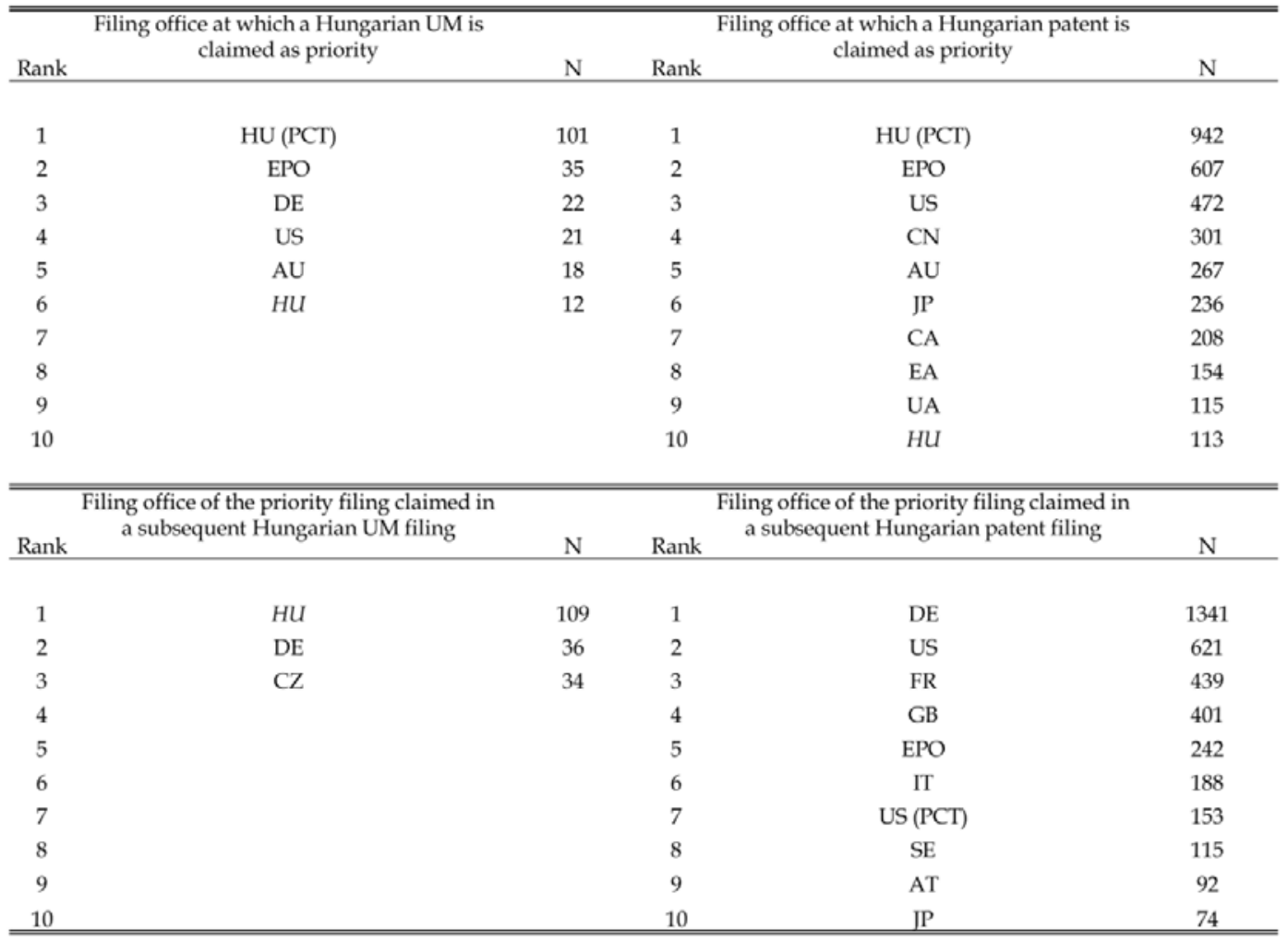

Table A.10 International patent family dyads, Italy

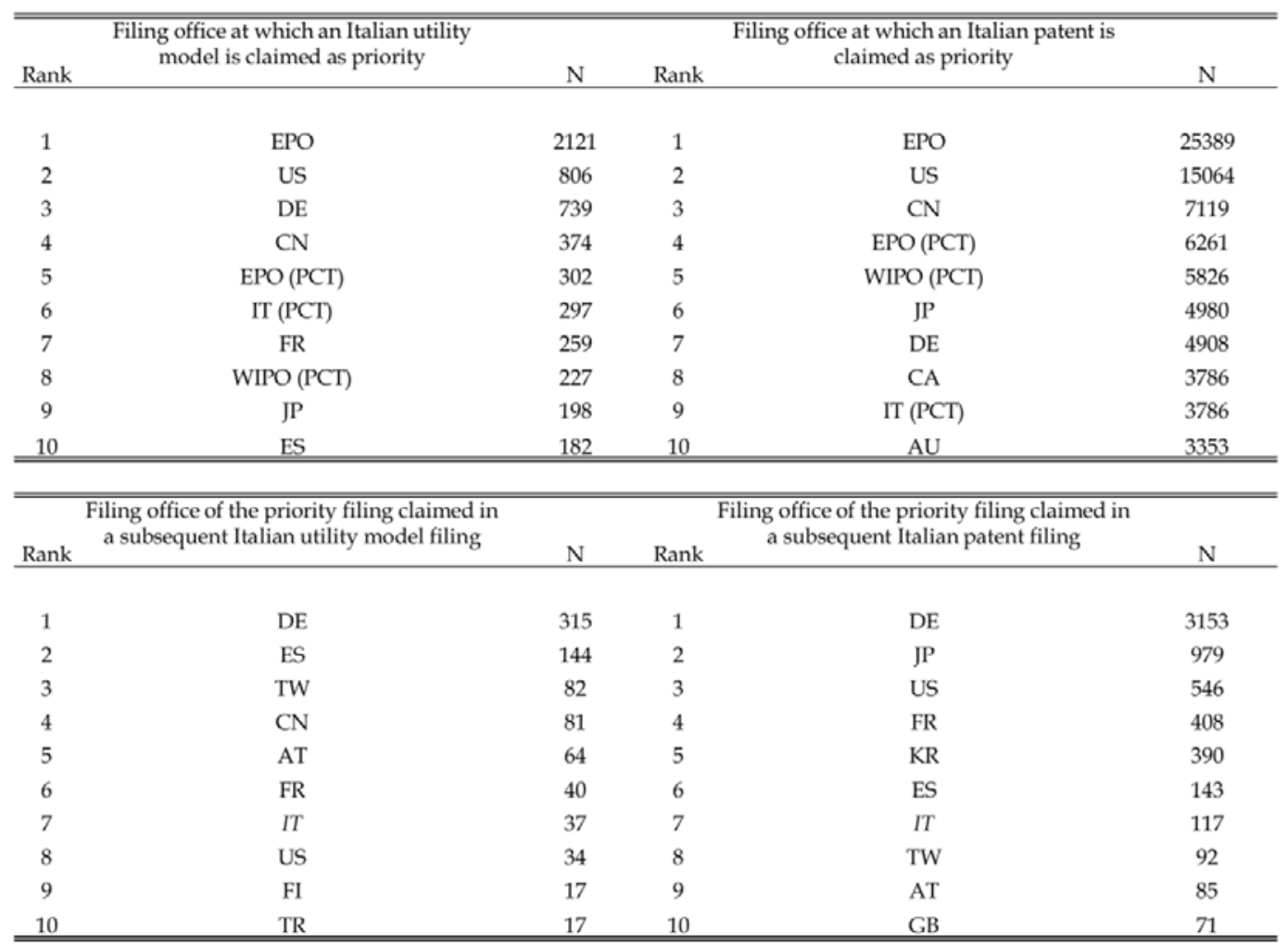


Table A.11 International patent family dyads, Poland

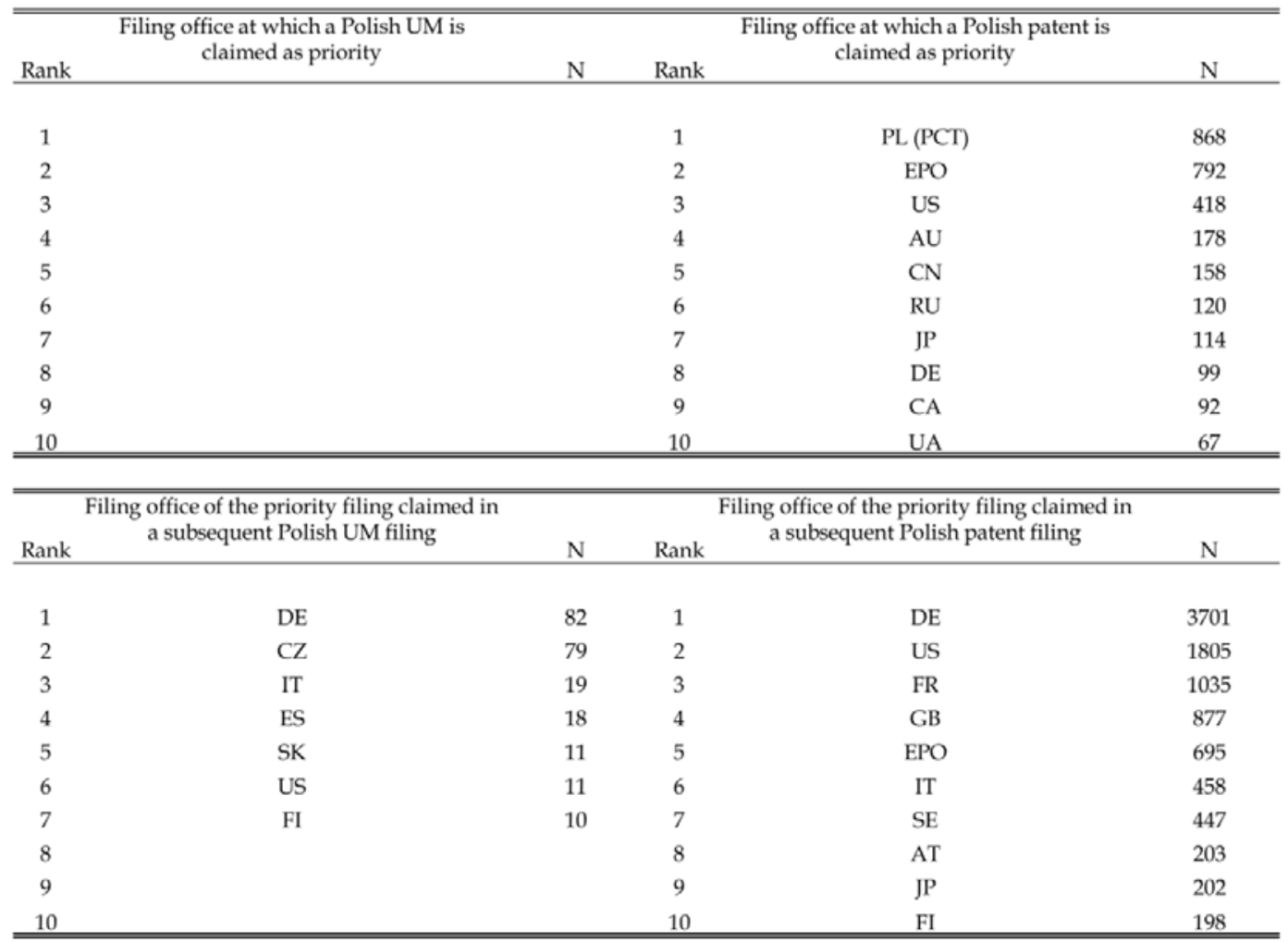

Table A.12 International patent family dyads, Portugal

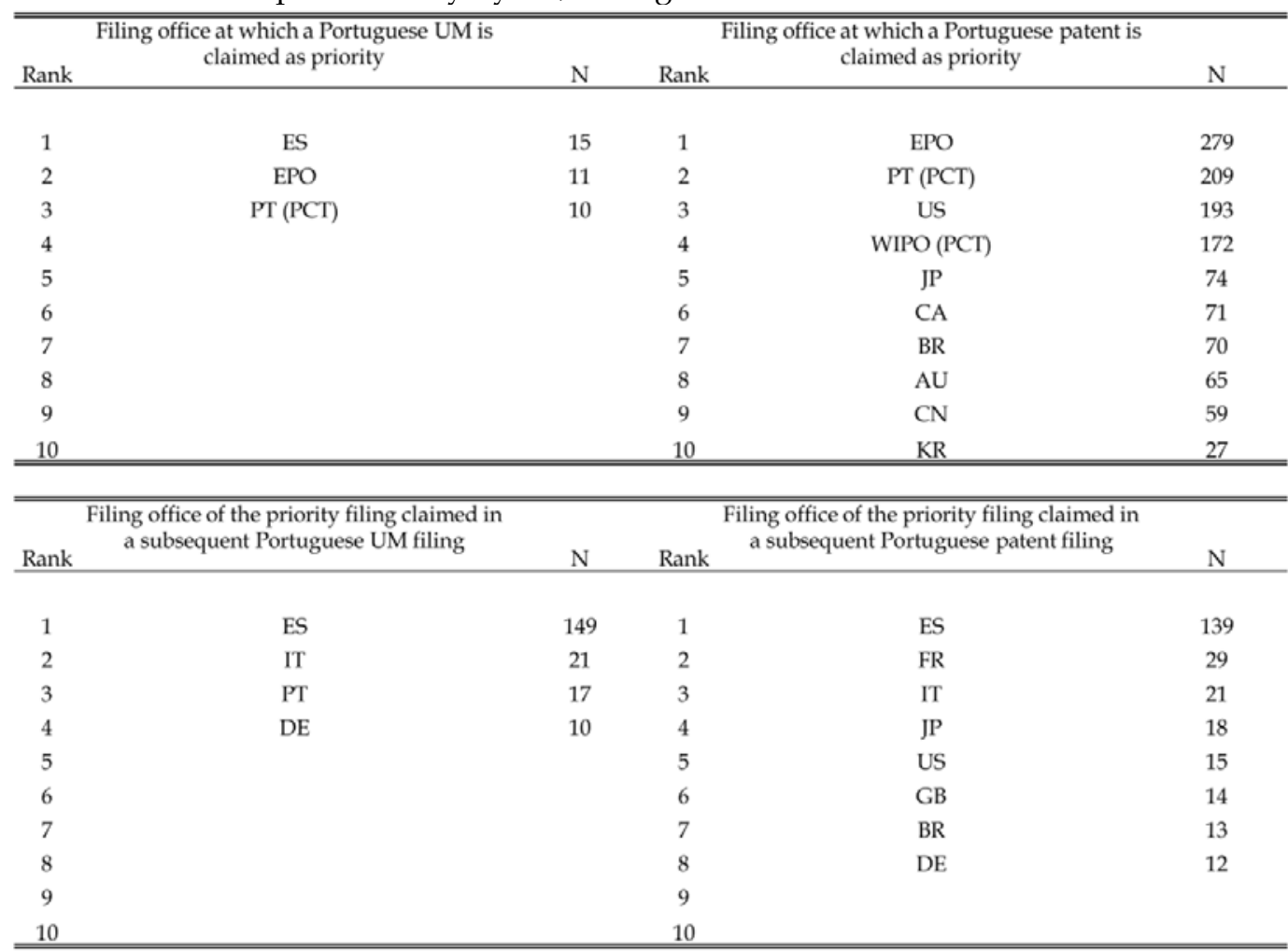


Table A.13 International patent family dyads, Slovakia

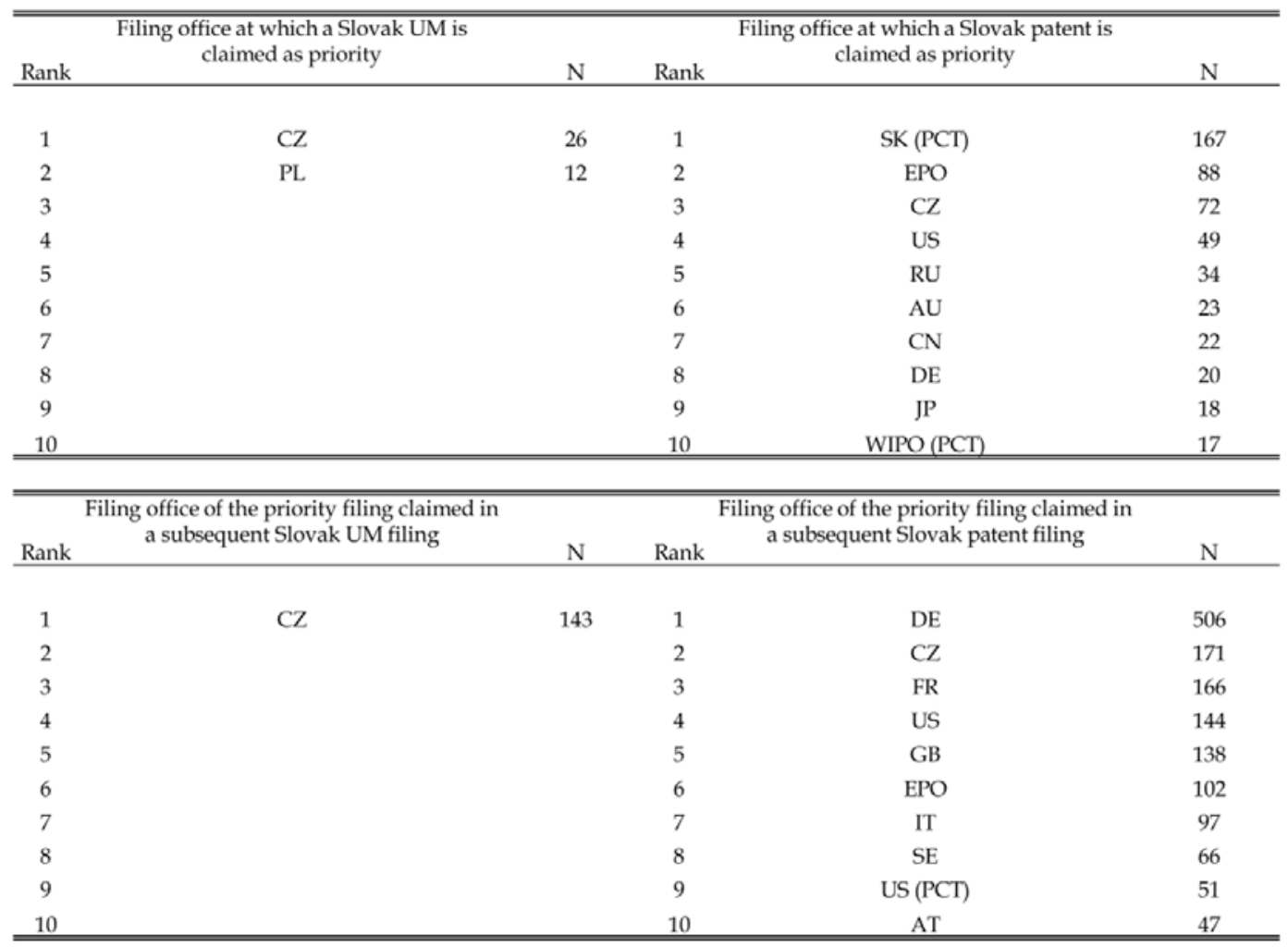


Table A.14 Characteristics of EPO patent applications with (single) patent or UM priorities, 2000-2010, all countries

\begin{tabular}{|c|c|c|c|c|c|c|}
\hline \multicolumn{7}{|c|}{ Priority filing type } \\
\hline & \multicolumn{2}{|c|}{ Utility model } & \multicolumn{2}{|c|}{ Patent } & \multicolumn{2}{|c|}{ Total } \\
\hline Applications & \multicolumn{2}{|c|}{16799} & \multicolumn{2}{|c|}{155923} & \multicolumn{2}{|c|}{172722} \\
\hline \multirow[t]{2}{*}{ Grants/Registrations } & \multicolumn{2}{|c|}{8756} & \multicolumn{2}{|c|}{86786} & \multicolumn{2}{|c|}{95542} \\
\hline & \multicolumn{2}{|c|}{ Utility model } & \multicolumn{2}{|c|}{ Patent } & \multirow{2}{*}{$\begin{array}{c}\text { Difference of } \\
\text { means }\end{array}$} & \multirow[b]{2}{*}{ Std. Err. } \\
\hline Characteristic & Mean & Std. Dev. & Mean & Std. Dev. & & \\
\hline Granted & 0.521 & 0.500 & 0.557 & 0.497 & $0.035^{\text {k*k}}$ & 0.004 \\
\hline Cited & 0.753 & 0.431 & 0.824 & 0.381 & $0.071^{\star \star \star}$ & 0.003 \\
\hline Number of citations & 3.375 & 5.283 & 5.012 & 7.751 & $1.637^{\star \star \star}$ & 0.061 \\
\hline Patent family size & 4.346 & 2.828 & 5.478 & 3.522 & $1.132^{\star * *}$ & 0.028 \\
\hline Timespan & 402.838 & 275.076 & 511.228 & 434.891 & $108.390^{* * *}$ & 3.427 \\
\hline Number of inventors & 1.622 & 1.115 & 2.328 & 1.625 & $0.706^{\star \star \star}$ & 0.013 \\
\hline Individual applicant & 0.179 & 0.383 & 0.074 & 0.262 & $-0.105^{\star \star \star}$ & 0.002 \\
\hline PCT filing & 0.282 & 0.450 & 0.529 & 0.499 & $0.247^{* * *}$ & 0.004 \\
\hline Domestic applicant & 0.879 & 0.326 & 0.895 & 0.307 & $0.016^{\text {**** }}$ & 0.003 \\
\hline Filing lag & 323.622 & 77.396 & 333.528 & 62.733 & $9.906^{* * *}$ & 0.522 \\
\hline Grant lag & 1482.187 & 674.175 & 1579.33 & 712.744 & $97.144^{\star \star \star \star}$ & 7.953 \\
\hline
\end{tabular}

Notes: All other variables show the statistics for applications sample (172722 obs.) except grant lag is reported for subsample of granted EPO patents (95542 obs.). ${ }^{* * *}$ indicate statistical significance at a $1 \%$ significance level. 
Table A.15 Results for granted and not-granted subsamples

(A) Germany excluded

\begin{tabular}{|c|c|c|c|c|c|c|c|c|}
\hline Dependent variable & & ted & Number & f citations & Patent $\mathrm{f}$ & mily size & Tim & espan \\
\hline Model & & bit & Neg & bin. & $\mathrm{Ne}$ & bin. & $\operatorname{Cox}$ & $\mathrm{PH}$ \\
\hline Estimate & M.E. & M.E. & Coeff. & Coeff. & Coeff. & Coeff. & Hazar & d Ratio \\
\hline Sample & German & excluded & Germany & excluded & German & excluded & Germany & excluded \\
\hline Subsample & $\begin{array}{c}\text { Granted } \\
\text { (1) }\end{array}$ & $\begin{array}{c}\text { Not granted } \\
\text { (2) }\end{array}$ & $\begin{array}{c}\text { Granted } \\
\text { (3) }\end{array}$ & $\begin{array}{l}\text { Not granted } \\
\text { (4) }\end{array}$ & $\begin{array}{c}\text { Granted } \\
\text { (5) }\end{array}$ & $\begin{array}{c}\text { Not granted } \\
\text { (6) }\end{array}$ & $\begin{array}{c}\text { Granted } \\
(7)\end{array}$ & $\begin{array}{c}\text { Not granted } \\
(8) \\
\end{array}$ \\
\hline D(UM Priority) & $\begin{array}{c}-0.058^{* * *} \\
(0.009)\end{array}$ & $\begin{array}{c}-0.051^{* * *} \\
(0.010)\end{array}$ & $\begin{array}{c}-0.269^{* * \star} \\
(0.037)\end{array}$ & $\begin{array}{c}-0.313^{* * *} \\
(0.035)\end{array}$ & $\begin{array}{c}-0.035^{* * *} \\
(0.012)\end{array}$ & $\begin{array}{c}-0.107^{* \star *} \\
(0.014)\end{array}$ & $\begin{array}{l}1.142^{* * *} \\
(0.030)\end{array}$ & $\begin{array}{l}1.152^{* * *} \\
(0.026)\end{array}$ \\
\hline $\mathrm{D}$ (Individual applicant) & $\begin{array}{c}-0.043^{\star \star \star \star} \\
(0.008)\end{array}$ & $\begin{array}{c}-0.039^{\star \star \star} \\
(0.008)\end{array}$ & $\begin{array}{c}-0.295^{\star \star \star \star} \\
(0.028)\end{array}$ & $\begin{array}{c}-0.206^{\star * \star} \\
(0.028)\end{array}$ & $\begin{array}{c}-0.111^{\star \star \star \star} \\
(0.011)\end{array}$ & 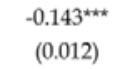 & $\begin{array}{l}1.122^{* * \star} \\
(0.025)\end{array}$ & $\begin{array}{c}1.023 \\
(0.018)\end{array}$ \\
\hline Number of inventors & $\begin{array}{l}0.013^{-1 k} \\
(0.002)\end{array}$ & $\begin{array}{l}0.018^{*-1+k} \\
(0.003)\end{array}$ & $\begin{array}{l}0.075^{\text {kntk }} \\
(0.008)\end{array}$ & $\begin{array}{l}0.083^{\text {thk }} \\
(0.008)\end{array}$ & $\begin{array}{l}0.014^{n+k} \\
(0.003)\end{array}$ & $\begin{array}{l}0.027 \\
(0.004)\end{array}$ & $\begin{array}{l}0.965^{\text {k*k }} \\
(0.005)\end{array}$ & $\begin{array}{l}0.951^{\text {*t* }} \\
(0.005)\end{array}$ \\
\hline D(PCT family) & $\begin{array}{l}0.063^{\text {tkk}} \\
(0.006)\end{array}$ & $\begin{array}{l}0.102^{\star \star \star \star} \\
(0.007)\end{array}$ & $\begin{array}{l}0.247^{\text {ktk}} \\
(0.019)\end{array}$ & $\begin{array}{l}0.402^{\text {tkt }} \\
(0.022)\end{array}$ & $\begin{array}{l}0.504^{\star \star \star \star} \\
(0.007)\end{array}$ & $\begin{array}{l}0.837^{\star \star \star \star} \\
(0.010)\end{array}$ & $\begin{array}{l}0.533^{\star * \star *} \\
(0.009)\end{array}$ & $\begin{array}{l}0.600^{+* *} \\
(0.010)\end{array}$ \\
\hline Constant & & & $\begin{array}{l}1.785^{\text {**k}} \\
(0.130)\end{array}$ & $\begin{array}{l}1.449^{* k \hbar} \\
(0.154)\end{array}$ & $\begin{array}{l}1.775^{\text {k+k }} \\
(0.039)\end{array}$ & $\begin{array}{l}0.851^{\text {nth }} \\
(0.070)\end{array}$ & & \\
\hline Observations & 19422 & 20469 & 19422 & 20469 & 19422 & 20469 & 19409 & 20455 \\
\hline Log likelihood & 8795.34 & -11777.22 & -49265.34 & -44121.39 & -47634.15 & -39232.74 & -171468.68 & -182976.17 \\
\hline Pseudo R2 & 0.05 & 0.04 & & & & & & \\
\hline
\end{tabular}

Notes: The sample consists of EPO filings filed 2000-2010, which claim a single patent or single utility model priority filed between 2000-2010 in Austria, Czech Republic, Denmark, Finland, Hungary, Italy or Spain. All models include technology field dummies, filing year dummies and priority author dummies as controls. Robust standard errors in parentheses. ${ }^{* * *}, * *$ and ${ }^{*}$ refer to $1 \%, 5 \%$ and $10 \%$ significance levels respectively.

(B) Germany

\begin{tabular}{|c|c|c|c|c|c|c|c|c|}
\hline Dependent variable & \multicolumn{2}{|c|}{ Cited } & \multicolumn{2}{|c|}{ Number of citations } & \multicolumn{2}{|c|}{ Patent family size } & \multicolumn{2}{|c|}{ Timespan } \\
\hline Model & \multicolumn{2}{|c|}{ Probit } & \multicolumn{2}{|c|}{ Neg. bin. } & \multicolumn{2}{|c|}{ Neg. bin. } & \multicolumn{2}{|c|}{ Cox $\mathrm{PH}$} \\
\hline Estimate & M.E. & M.E. & Coeff. & Coeff. & Coeff. & Coeff. & Hazar & d Ratio \\
\hline Sample & \multicolumn{2}{|c|}{ Germany } & \multicolumn{2}{|c|}{ Germany } & \multicolumn{2}{|c|}{ Germany } & \multicolumn{2}{|c|}{ Germany } \\
\hline Subsample & $\begin{array}{c}\text { Granted } \\
\text { (1) }\end{array}$ & $\begin{array}{c}\text { Not granted } \\
\text { (2) }\end{array}$ & $\begin{array}{c}\text { Granted } \\
\text { (3) }\end{array}$ & $\begin{array}{c}\text { Not granted } \\
\text { (4) }\end{array}$ & $\begin{array}{c}\text { Granted } \\
\text { (5) }\end{array}$ & $\begin{array}{c}\text { Not granted } \\
(6)\end{array}$ & $\begin{array}{c}\text { Granted } \\
(7)\end{array}$ & $\begin{array}{c}\text { Not granted } \\
(8) \\
\end{array}$ \\
\hline D(UM Priority) & $\begin{array}{c}-0.024^{\star \star \star \star *} \\
(0.004)\end{array}$ & $\begin{array}{c}-0.022^{* \star \hbar *} \\
(0.006)\end{array}$ & $\begin{array}{c}-0.151^{\text {****}} \\
(0.016)\end{array}$ & $\begin{array}{c}-0.178^{\text {nkxt}} \\
(0.021)\end{array}$ & $\begin{array}{l}-0.009 \\
(0.006)\end{array}$ & $\begin{array}{c}-0.095^{* * *} \\
(0.009)\end{array}$ & $\begin{array}{l}1.094^{\star * \hbar *} \\
(0.014)\end{array}$ & $\begin{array}{l}1.134^{* \times \hbar *} \\
(0.016)\end{array}$ \\
\hline $\mathrm{D}$ (Individual applicant) & $\begin{array}{c}-0.043^{\text {tkkk}} \\
(0.005)\end{array}$ & $\begin{array}{c}-0.049^{\text {tkik }} \\
(0.006)\end{array}$ & $\begin{array}{c}-0.249^{\text {knk }} \\
(0.023)\end{array}$ & $\begin{array}{c}-0.239^{\text {knk }} \\
(0.025)\end{array}$ & $\begin{array}{c}-0.066^{* k \star k} \\
(0.009)\end{array}$ & $\begin{array}{c}-0.156^{\star k *} \\
(0.012)\end{array}$ & $\begin{array}{l}0.968^{\star *} \\
(0.015)\end{array}$ & $\begin{array}{c}0.914^{\text {*h+k }} \\
(0.013)\end{array}$ \\
\hline Number of inventors & $\begin{array}{l}0.010^{\star \star \star \hbar} \\
(0.002)\end{array}$ & $\begin{array}{l}0.016^{\star \star \star} \\
(0.001)\end{array}$ & $\begin{array}{l}0.070^{\star \star \star} \\
(0.003)\end{array}$ & $\begin{array}{c}0.083^{\star * \hbar \hbar} \\
(0.004)\end{array}$ & $\begin{array}{l}0.014^{\star \star \star \star} \\
(0.001)\end{array}$ & $\begin{array}{c}0.026^{\star \star \star} \\
(0.002)\end{array}$ & $\begin{array}{c}0.980^{\star \star \hbar \hbar} \\
(0.002)\end{array}$ & $\begin{array}{c}0.976^{\star \star \star \star} \\
(0.003)\end{array}$ \\
\hline D(PCT family) & $\begin{array}{c}0.063^{* \star \star \hbar} \\
(0.002)\end{array}$ & $\begin{array}{c}0.094^{* * * *} \\
(0.003)\end{array}$ & $\begin{array}{l}0.273^{\text {*n**}} \\
(0.009)\end{array}$ & $\begin{array}{c}0.352^{* * * *} \\
(0.012)\end{array}$ & $\begin{array}{c}0.503^{\star * *} \\
(0.003)\end{array}$ & $\begin{array}{c}0.742^{\star * \star *} \\
(0.005)\end{array}$ & $\begin{array}{c}0.559^{* * \hbar} \\
(0.005)\end{array}$ & $\begin{array}{c}0.639^{* * *} \\
(0.006)\end{array}$ \\
\hline Constant & & & $\begin{array}{l}1.924^{* * *} \\
(0.050)\end{array}$ & $\begin{array}{l}1.433^{\star * \star} \\
(0.079)\end{array}$ & $\begin{array}{l}1.499^{\star \star * \star} \\
(0.023)\end{array}$ & $\begin{array}{c}0.949^{\star \star \star \star} \\
(0.036)\end{array}$ & & \\
\hline Observations & 76055 & 56732 & 76055 & 56732 & 76055 & 56732 & 75392 & 56065 \\
\hline Log likelihood & -28426.32 & -27495.16 & -210202.46 & -139265.14 & -171677.42 & -108203.31 & -767622.29 & -556405.98 \\
\hline Pseudo R2 & 0.06 & 0.05 & & & & & & \\
\hline
\end{tabular}

Notes: The sample consists of EPO filings filed 2000-2010, which claim a single patent or single utility model priority filed between 2000-2010 in Germany. All models include technology field dummies, filing year dummies and priority author dummies as controls. Robust standard errors in parentheses. ${ }^{* * *}$, ${ }^{* *}$ and * refer to $1 \%, 5 \%$ and $10 \%$ significance levels respectively. 
Table A.16 Excluding process inventions

\begin{tabular}{|c|c|c|c|c|c|c|c|c|c|c|}
\hline \multirow{5}{*}{$\begin{array}{l}\text { Dependent variable } \\
\text { Model } \\
\text { Estimate } \\
\text { Sample }\end{array}$} & \multicolumn{2}{|c|}{$\operatorname{Pr}($ Grant=1) } & \multicolumn{2}{|c|}{$\operatorname{Pr}($ Cited=1) } & \multicolumn{2}{|c|}{ Number of citations } & \multicolumn{2}{|c|}{ Patent family size } & \multicolumn{2}{|c|}{ Timespan } \\
\hline & \multicolumn{2}{|c|}{ Probit } & \multicolumn{2}{|c|}{ Probit } & \multicolumn{2}{|c|}{ Neg. bin. } & \multicolumn{2}{|c|}{ Zero-trunc. neg. bin. } & \multicolumn{2}{|c|}{ Cox PH } \\
\hline & \multicolumn{2}{|c|}{ M.E. } & \multicolumn{2}{|c|}{ M.E. } & \multicolumn{2}{|c|}{ Coeff. } & \multicolumn{2}{|c|}{ Coeff. } & \multicolumn{2}{|c|}{ Hazard Ratio } \\
\hline & $\begin{array}{l}\text { Germany } \\
\text { excluded }\end{array}$ & Germany & $\begin{array}{l}\text { Germany } \\
\text { excluded }\end{array}$ & Germany & $\begin{array}{l}\text { Germany } \\
\text { excluded }\end{array}$ & Germany & $\begin{array}{l}\text { Germany } \\
\text { excluded }\end{array}$ & Germany & $\begin{array}{l}\text { Germany } \\
\text { excluded }\end{array}$ & Germany \\
\hline & (1) & (2) & (3) & $(4)$ & (5) & (6) & (7) & $(8)$ & (9) & (10) \\
\hline D(UM Priority) & $-0.075^{\star * *}$ & $-0.024^{\star \star *}$ & $-0.065^{\star * *}$ & $-0.022^{* * *}$ & $-0.346^{* * *}$ & $-0.151^{* * *}$ & $-0.100^{* * *}$ & $-0.027^{\star * *}$ & $1.146^{\star \star \star *}$ & $1.097^{\star \star \star}$ \\
\hline & $(0.009)$ & $(0.005)$ & $(0.007)$ & $(0.004)$ & $(0.028)$ & $(0.014)$ & $(0.012)$ & $(0.006)$ & $(0.021)$ & $(0.011)$ \\
\hline D(Individual applicant) & $-0.145^{\star * \star}$ & $-0.108^{\star * *}$ & $-0.050^{\star \star \star}$ & $-0.051^{\star * *}$ & $-0.304^{* \star \star}$ & $-0.280^{\star \star \star}$ & $-0.215^{\star * \star}$ & $-0.147^{* * *}$ & $1.099^{\star \star \star}$ & $0.938^{* \star \star}$ \\
\hline & $(0.008)$ & $(0.007)$ & $(0.007)$ & $(0.005)$ & $(0.024)$ & $(0.020)$ & $(0.011)$ & $(0.009)$ & $(0.017)$ & $(0.012)$ \\
\hline Number of inventors & $0.007^{* * *}$ & -0.001 & $0.016^{\star * *}$ & $0.012^{\star \star *}$ & $0.077^{\star * *}$ & $0.074^{\star \star \star}$ & $0.022^{\star \star *}$ & $0.019^{\star \star *}$ & $0.959^{\star \star \star *}$ & $0.976^{\star \star \star *}$ \\
\hline & $(0.002)$ & $(0.001)$ & $(0.003)$ & $(0.001)$ & $(0.007)$ & $(0.003)$ & $(0.003)$ & $(0.001)$ & $(0.005)$ & $(0.002)$ \\
\hline D(PCT family) & $0.110^{\star \star \star}$ & $0.066^{\star \star \star}$ & $0.096^{\star \star *}$ & $0.083^{\star \star \star}$ & $0.353^{\star \star *}$ & $0.327^{\star \star \star *}$ & $0.695^{\star \star \star *}$ & $0.610^{\star \star \star *}$ & $0.548^{\star \star *}$ & $0.569^{\star \star \star}$ \\
\hline & $(0.006)$ & $(0.003)$ & $(0.006)$ & $(0.003)$ & $(0.018)$ & $(0.009)$ & $(0.008)$ & $(0.004)$ & $(0.008)$ & $(0.005)$ \\
\hline Constant & & & & & $1.761^{\star \star *}$ & $1.750^{\star \star \star *}$ & $1.565^{\star * *}$ & $1.290^{\star * \star}$ & & \\
\hline & & & & & $(0.117)$ & $(0.049)$ & $(0.049)$ & $(0.026)$ & & \\
\hline Observations & 26132 & 84842 & 26132 & 84842 & 26132 & 84842 & 26132 & 84842 & 26114 & 84054 \\
\hline Log likelihood & -17070.43 & -55137.03 & -13781.23 & -36595.89 & -60587.92 & -221697.74 & -59979.115 & -184303.07 & -239170.13 & -866143.68 \\
\hline Pseudo R2 & 0.06 & 0.04 & 0.05 & 0.06 & & & & & & \\
\hline
\end{tabular}


Table A.17 Filing and grant lags, alternative model specifications

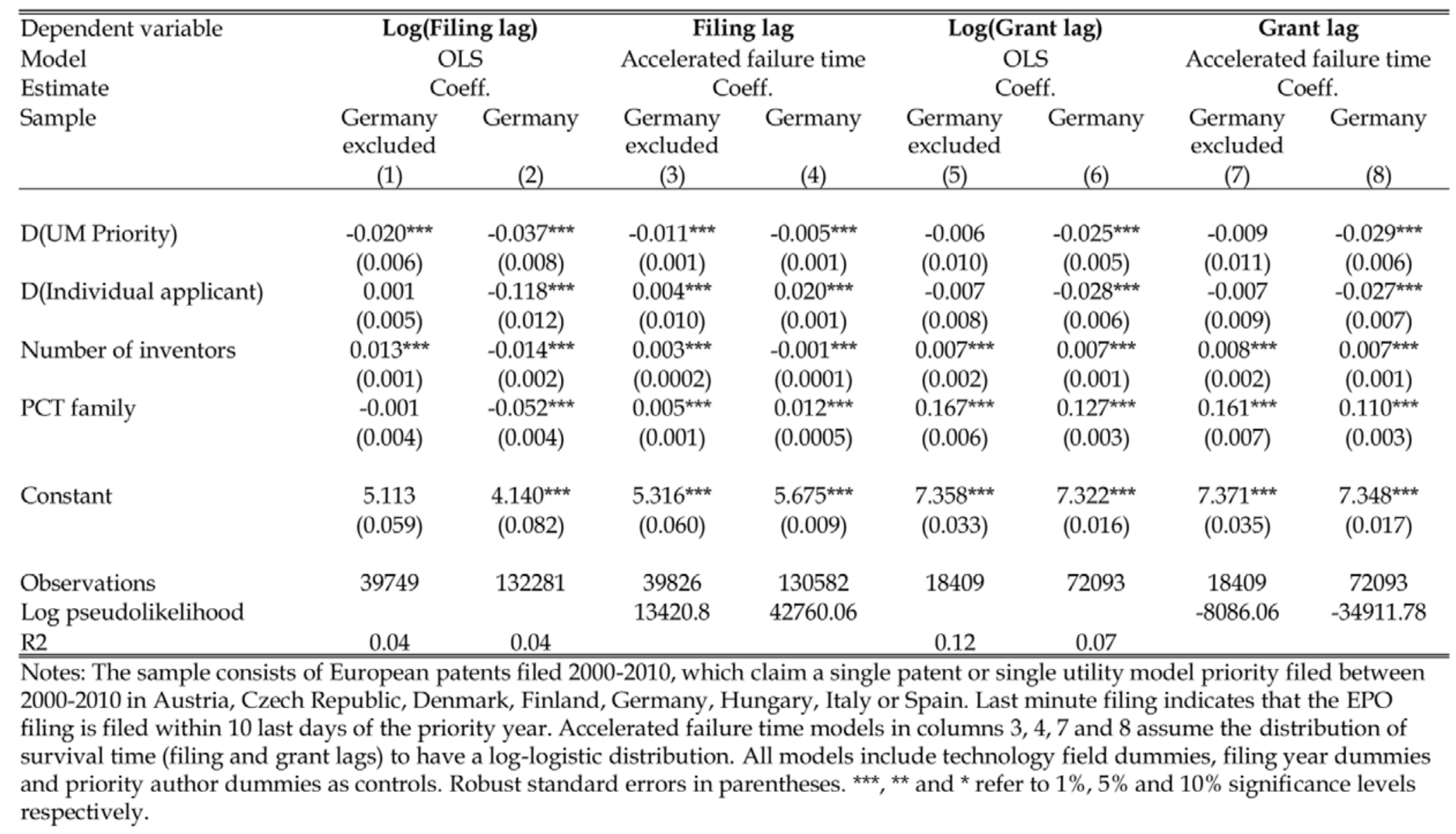


Table A.18 Patent family quality, all countries

\begin{tabular}{lccccc}
\hline Dependent variable & $\operatorname{Pr}($ Grant=1) & $\operatorname{Pr}($ Cited=1) & $\begin{array}{c}\text { Number of } \\
\text { citations }\end{array}$ & Patent family size & Timespan \\
Model & Probit & Probit & Neg. bin. & Zero-inf. neg. bin. & Cox PH \\
Estimate & M.E. & M.E. & Coeff. & Coeff. & Hazard Ratio \\
& $(1)$ & $(2)$ & $(3)$ & $(4)$ & $(5)$ \\
\hline & & & & & \\
D(UM Priority) & $-0.028^{* * *}$ & $-0.033^{* * *}$ & $-0.203^{* * *}$ & $-0.042^{* * *}$ & $1.121^{* * *}$ \\
& $(0.004)$ & $(0.003)$ & $(0.012)$ & $(0.005)$ & $(0.010)$ \\
D(Individual applicant) & $-0.119^{* * *}$ & $-0.050^{* * *}$ & $-0.285^{* * *}$ & $-0.169^{* * *}$ & 1.008 \\
& $(0.004)$ & $(0.003)$ & $(0.013)$ & $(0.006)$ & $(0.008)$ \\
Number of inventors & 0.001 & $0.014^{* * *}$ & $0.077^{* * *}$ & $0.018^{* * *}$ & $0.975^{* * *}$ \\
& $(0.001)$ & $(0.001)$ & $(0.002)$ & $(0.001)$ & $(0.002)$ \\
D(PCT family) & $0.076^{* * *}$ & $0.083^{* * *}$ & $0.323^{* * *}$ & $0.624^{* * *}$ & $0.583^{* * *}$ \\
Constant & $(0.002)$ & $(0.002)$ & $(0.007)$ & $(0.003)$ & $(0.003)$ \\
& & & $1.610^{* * *}$ & $1.443^{* * *}$ & \\
Observations & & & $(0.044)$ & $(0.021)$ & \\
Log likelihood & 172678 & 172678 & 172678 & 172678 & 171321 \\
Pseudo R2 & -112955.40 & -77162.10 & -444845.86 & -383577.80 & -1888439.90 \\
\hline
\end{tabular}

Notes: The sample consists of EPO filings filed 2000-2010, which claim a single patent or single utility model priority filed between 2000-2010 in Austria, Czech Republic, Denmark, Finland, Germany, Hungary, Italy or Spain. All models include technology field dummies, filing year dummies and priority author dummies as controls. Robust standard errors in parentheses. In columns 9 and 10 Cox $\mathrm{PH}$ models use Breslow method for ties. ${ }^{* * *},{ }^{* *}$ and ${ }^{*}$ refer to $1 \%, 5 \%$ and $10 \%$ significance levels respectively. 
Table A.19 Filing behavior and grant lags, all countries

\begin{tabular}{|c|c|c|c|c|}
\hline Dependent variable & Filing lag & $\begin{array}{l}\text { Lastminute } \\
\text { filing }\end{array}$ & $\begin{array}{l}\text { Filing within } \\
\text { first } 10 \text { days }\end{array}$ & Grant lag \\
\hline Model & Cox PH & Probit & Probit & Cox PH \\
\hline \multirow[t]{2}{*}{ Estimates } & Hazard Ratio & M.E. & M.E. & Hazard Ratio \\
\hline & (1) & (2) & (3) & (4) \\
\hline \multirow[t]{2}{*}{$\mathrm{D}$ (UM Priority) } & $0.941^{* * *}$ & 0.005 & -0.0005 & $1.042^{* * *}$ \\
\hline & $(0.008)$ & $(0.004)$ & $(0.001)$ & $(0.013)$ \\
\hline \multirow[t]{2}{*}{ D(Individual applicant) } & $0.747^{* * *}$ & $0.127^{* * *}$ & $0.012^{* * *}$ & $1.081^{* * *}$ \\
\hline & $(0.006)$ & $(0.005)$ & $(0.001)$ & $(0.015)$ \\
\hline \multirow[t]{2}{*}{ Number of inventors } & $1.010^{* * *}$ & $-0.004^{* * *}$ & $0.001^{* * *}$ & $0.984^{* * *}$ \\
\hline & $(0.002)$ & $(0.001)$ & $(0.0002)$ & $(0.002)$ \\
\hline \multirow[t]{2}{*}{ PCT family } & $0.810^{* * *}$ & $0.090^{* * *}$ & $0.008^{* * *}$ & $0.827^{* * *}$ \\
\hline & $(0.004)$ & $(0.002)$ & $(0.001)$ & $(0.006)$ \\
\hline Technology field dummies & Yes & Yes & Yes & Yes \\
\hline Filing year dummies & Yes & Yes & Yes & Yes \\
\hline Priority author dummies & Yes & Yes & Yes & Yes \\
\hline Observations & 170408 & 172323 & 167501 & 90453 \\
\hline Log likelihood & -1894840.00 & -112667.39 & -11284.54 & -939712.60 \\
\hline Pseudo R2 & & 0.06 & 0.11 & \\
\hline
\end{tabular}

Notes: The sample consists of European patents filed 2000-2010, which claim a single patent or single utility model priority filed between 2000-2010 in Austria, Czech Republic, Denmark, Finland, Germany, Hungary, Italy or Spain. Last minute filing indicates that the EPO filing is filed within 10 last days of the priority year. All models include technology field dummies, filing year dummies and priority author dummies as controls. Robust standard errors in parentheses. ${ }^{* * *}$, ** and * refer to $1 \%, 5 \%$ and $10 \%$ significance levels respectively. 
Fig. A.1 Total UM filings by filing office, 2000-2010
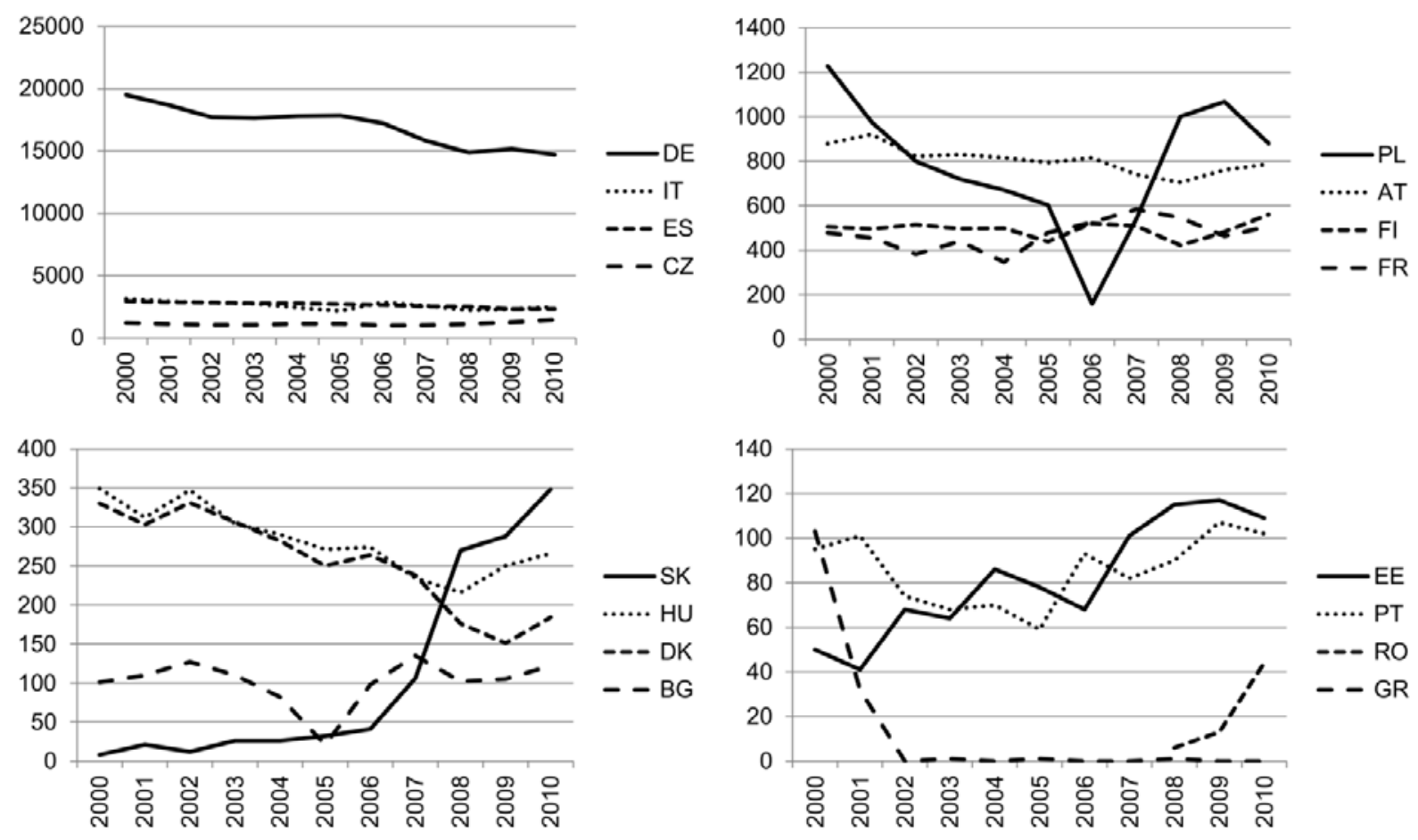

Source: Authors' calculations from PATSTAT 2016 April edition 
Fig. A.2 Distributions of filing lags between priorities and subsequent EPO filings

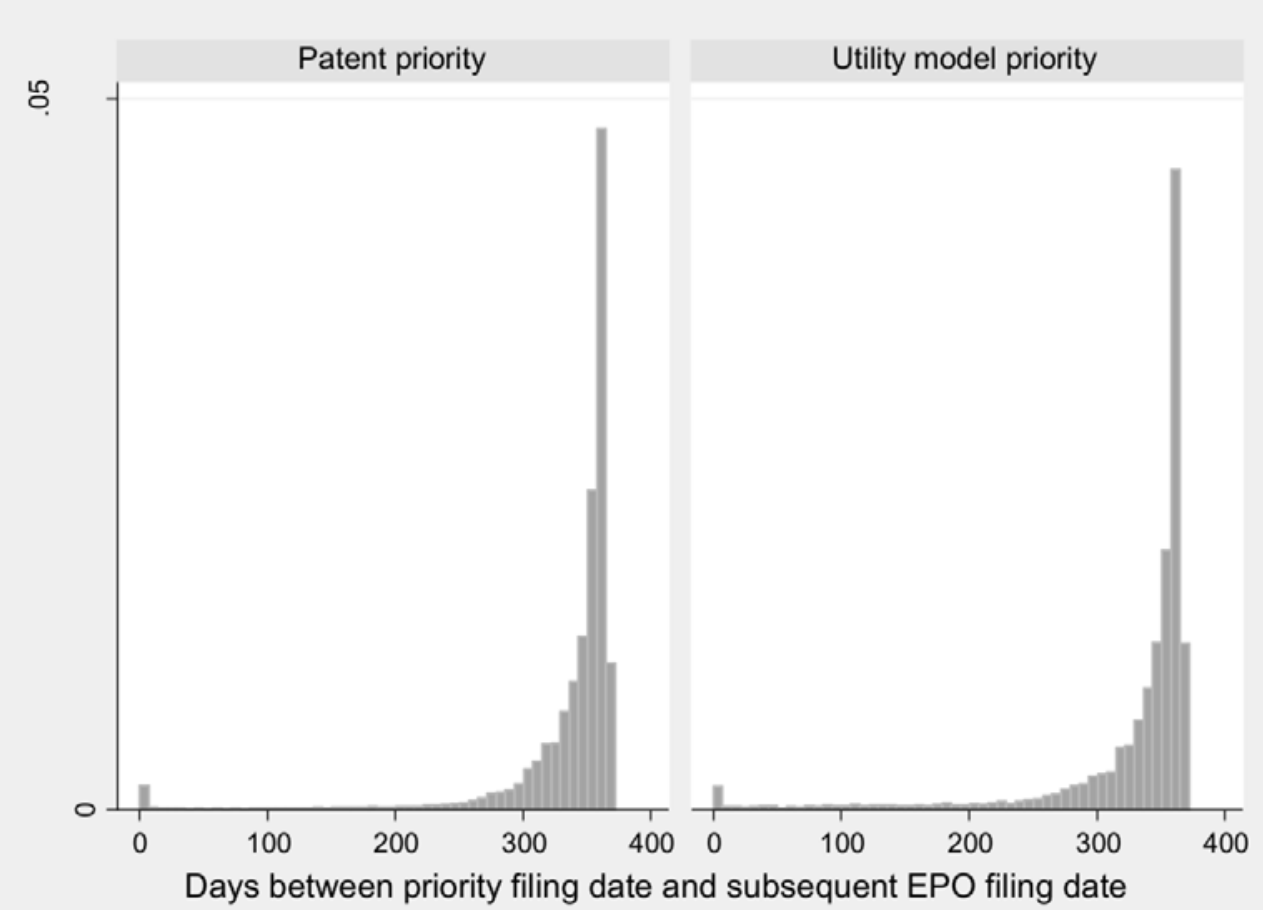

Notes: Patent families, which have longer than 12 months filing lag between the priority and subsequent EPO filing are excluded. 
Fig. A.3 Distributions of grant lags of EPO patents with patent and UM priorities

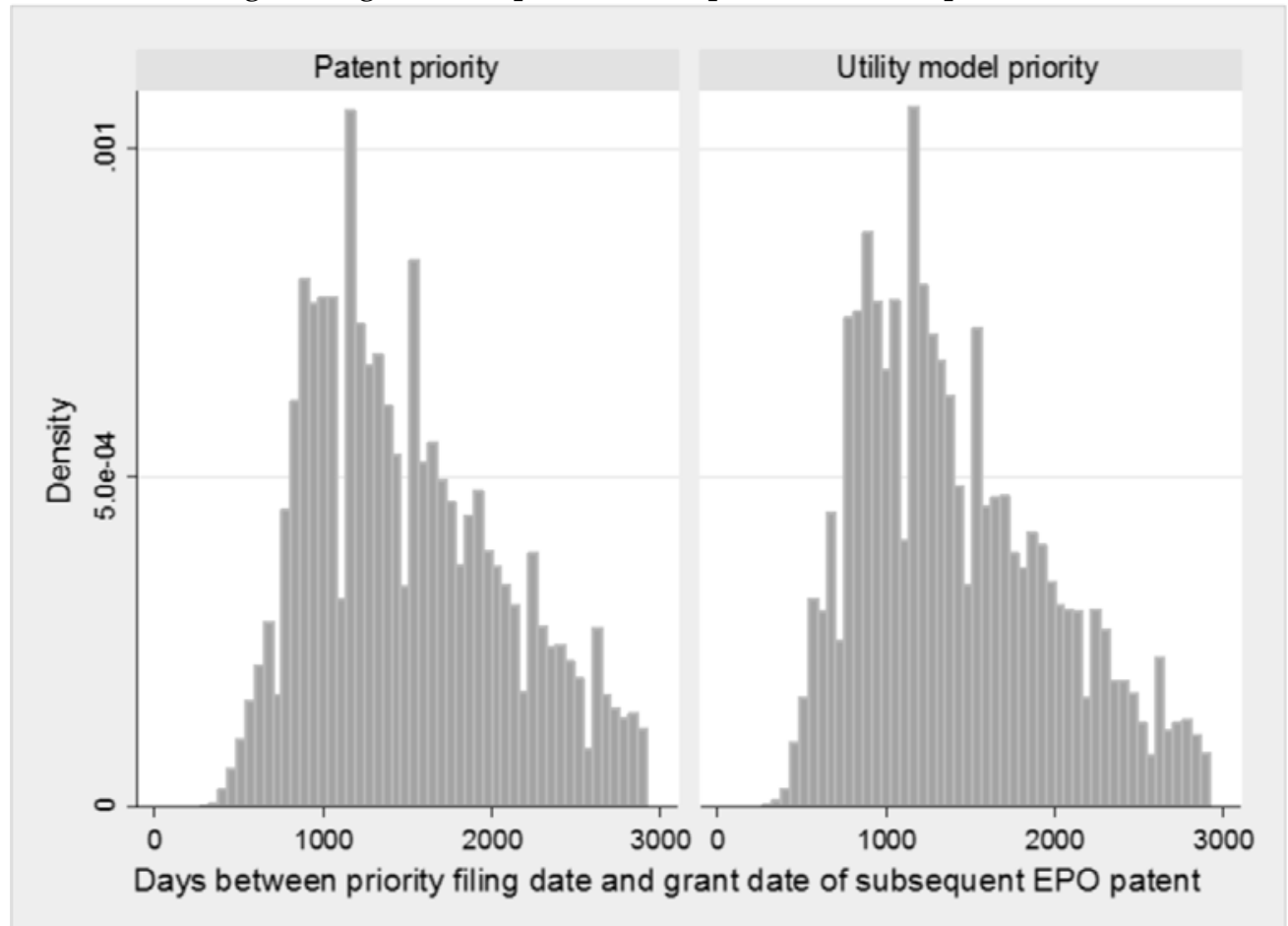

Notes: EPO patents with longer grant lags than 8 years are not reported. 
Fig. A.4 Distributions of timespans of EPO patent families with patent or UM priorities

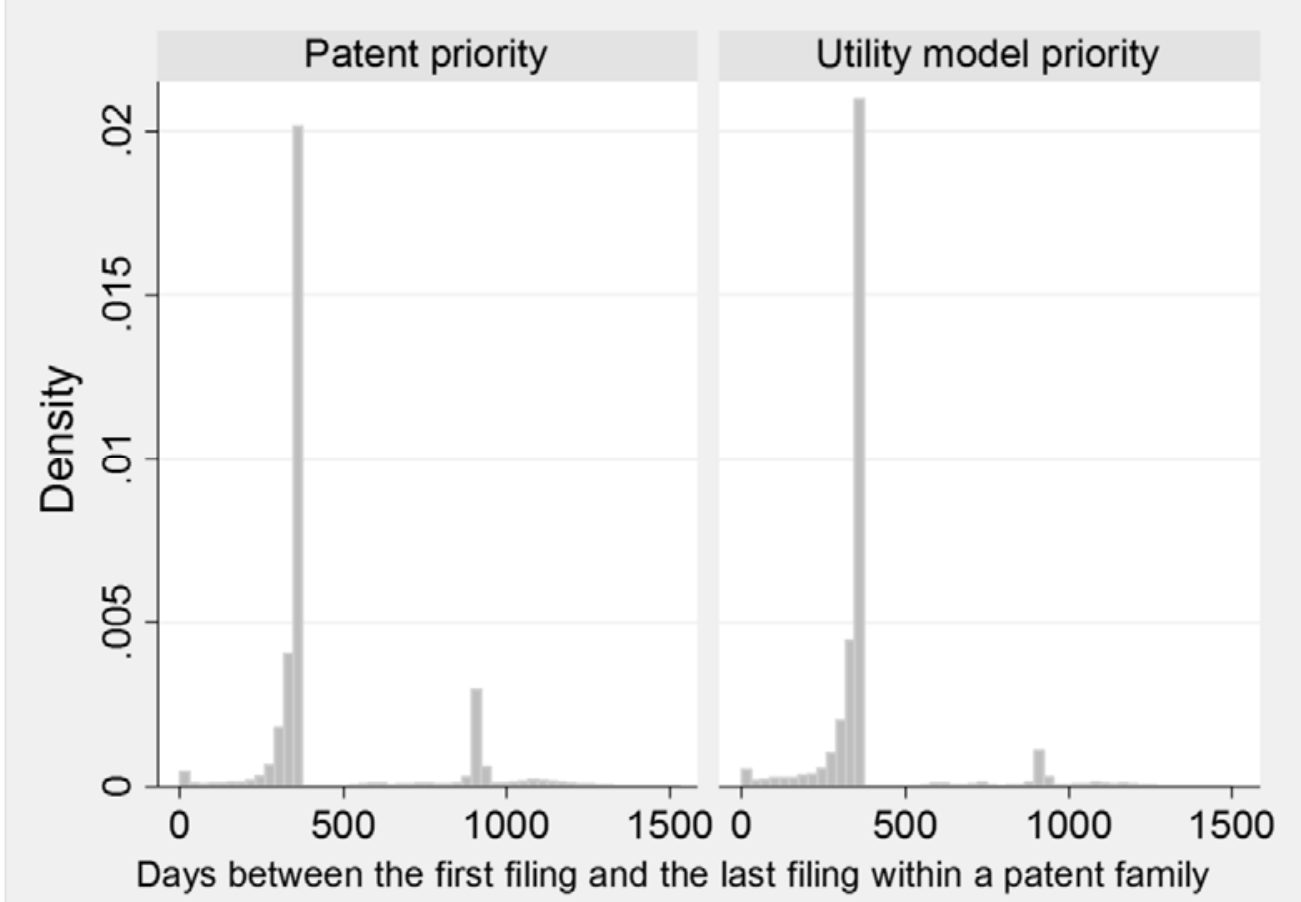

Notes: Patent families, which have longer than 1500 days timespans between the priority and the last filing within the family are not reported. 